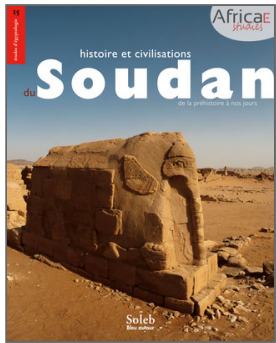

Histoire et civilisation du Soudan

De la préhistoire à nos jours

\title{
La campagne et les villages
}

\section{Odile Nicoloso et Nicolas Beaumé}

DOI : 10.4000/books.africae. 2957

Éditeur : Africae, Soleb, Bleu autour

Lieu d'édition : Paris, Khartoum

Année d'édition : 2017

Date de mise en ligne : 17 janvier 2022

Collection : Africae Studies

EAN électronique : 9782493207074

\section{(2) OpenEdition}

\section{Books}

http://books.openedition.org

\section{Référence électronique}

NICOLOSO, Odile ; BEAUMÉ, Nicolas. La campagne et les villages In : Histoire et civilisation du Soudan : De la préhistoire à nos jours [en ligne]. Paris, Khartoum : Africae, 2017 (généré le 28 janvier 2022).

Disponible sur Internet : <http://books.openedition.org/africae/2957>. ISBN : 9782493207074. DOI :

https://doi.org/10.4000/books.africae.2957. 

(2)

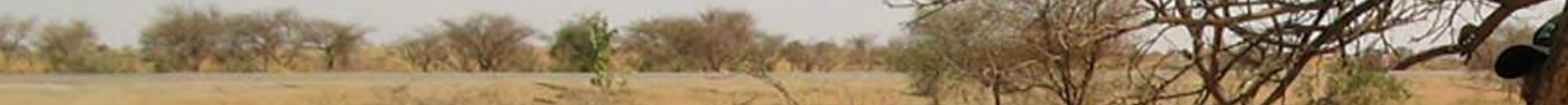

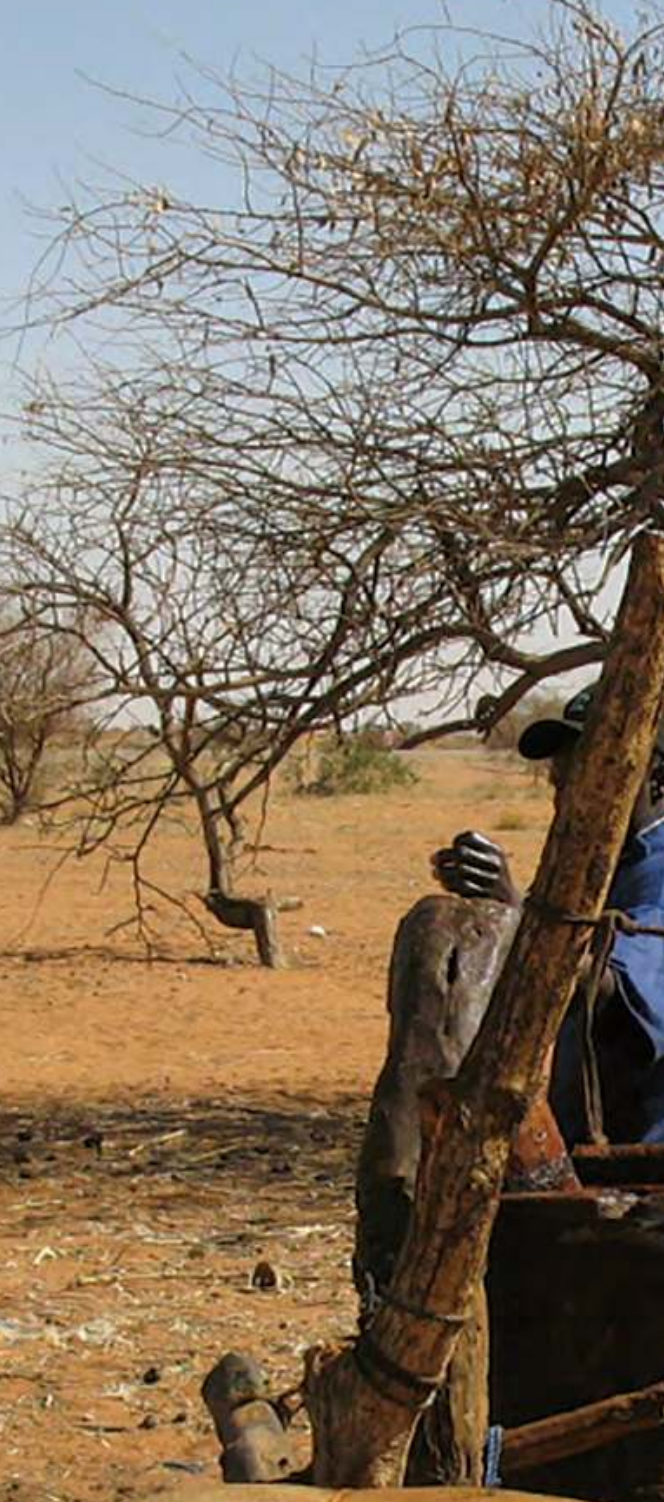

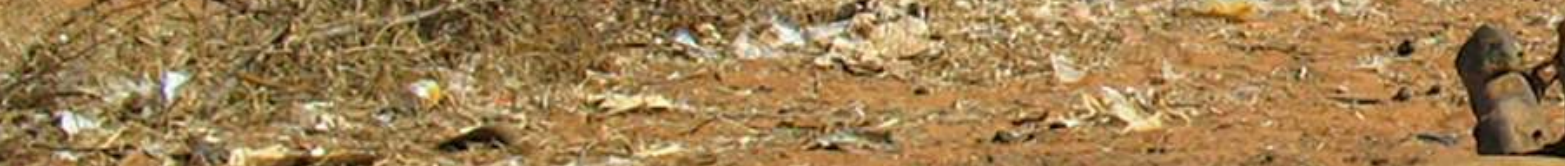

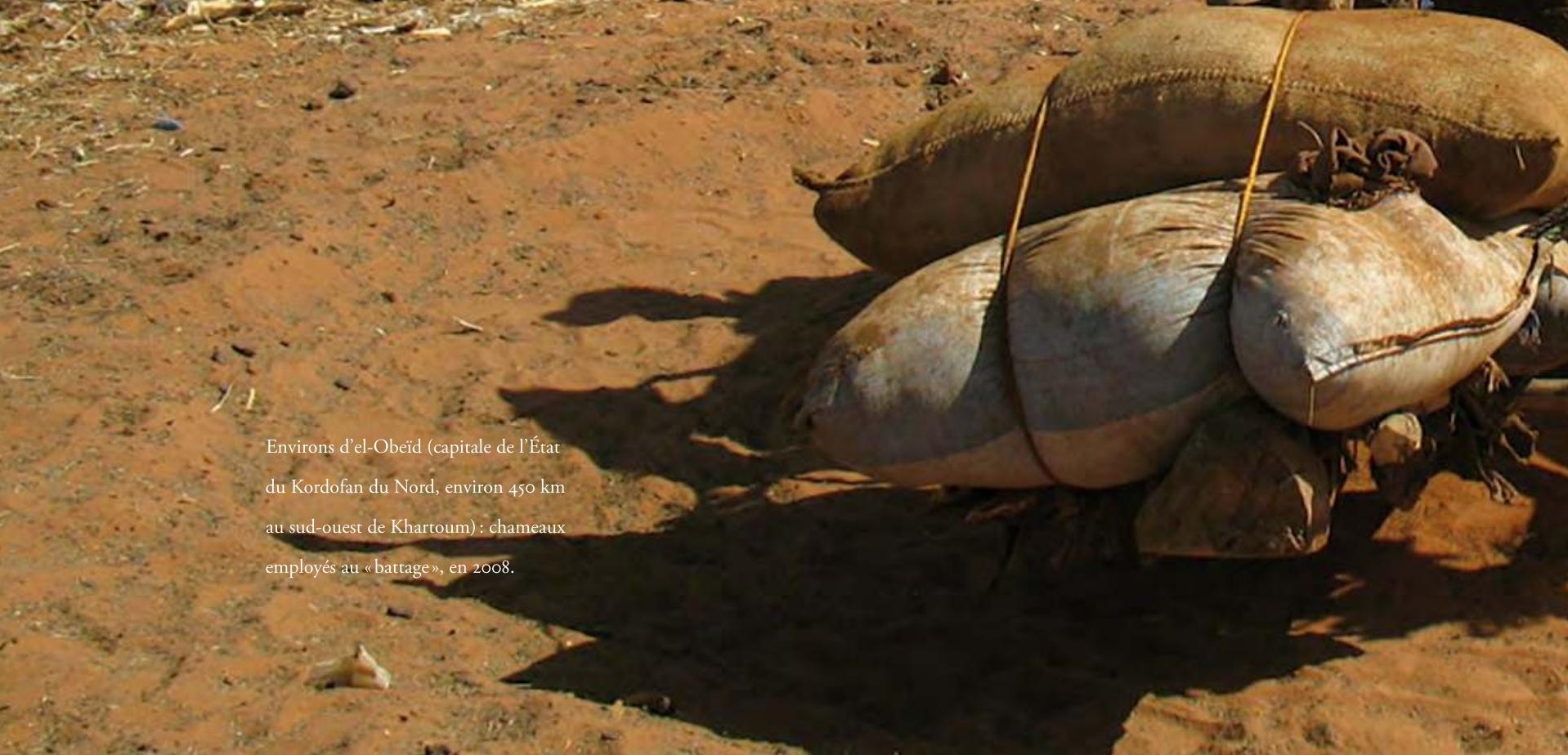




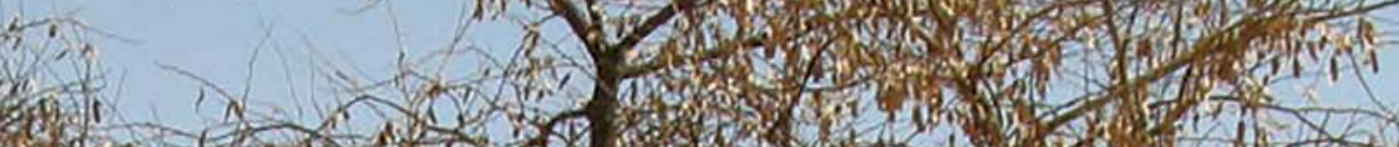

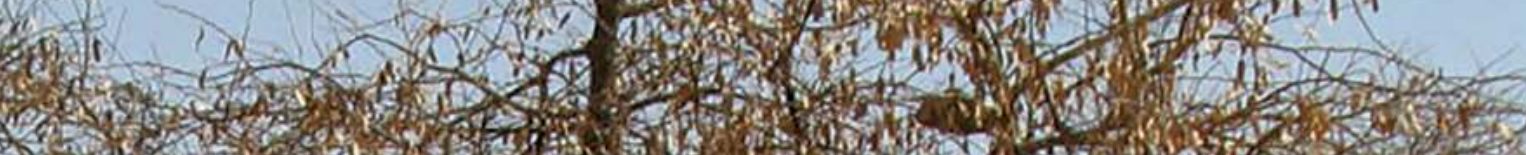

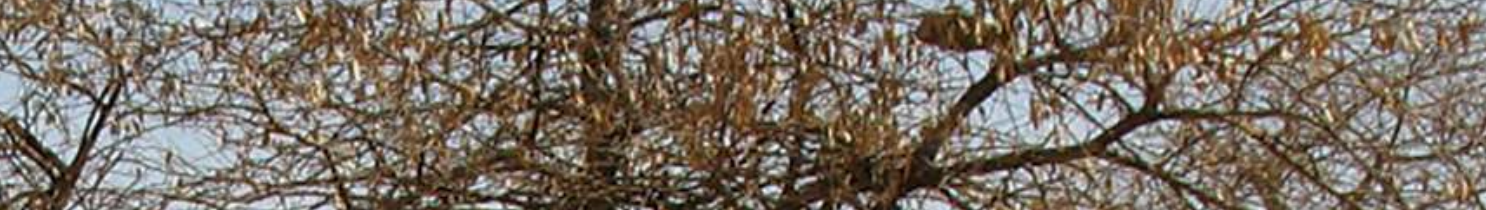

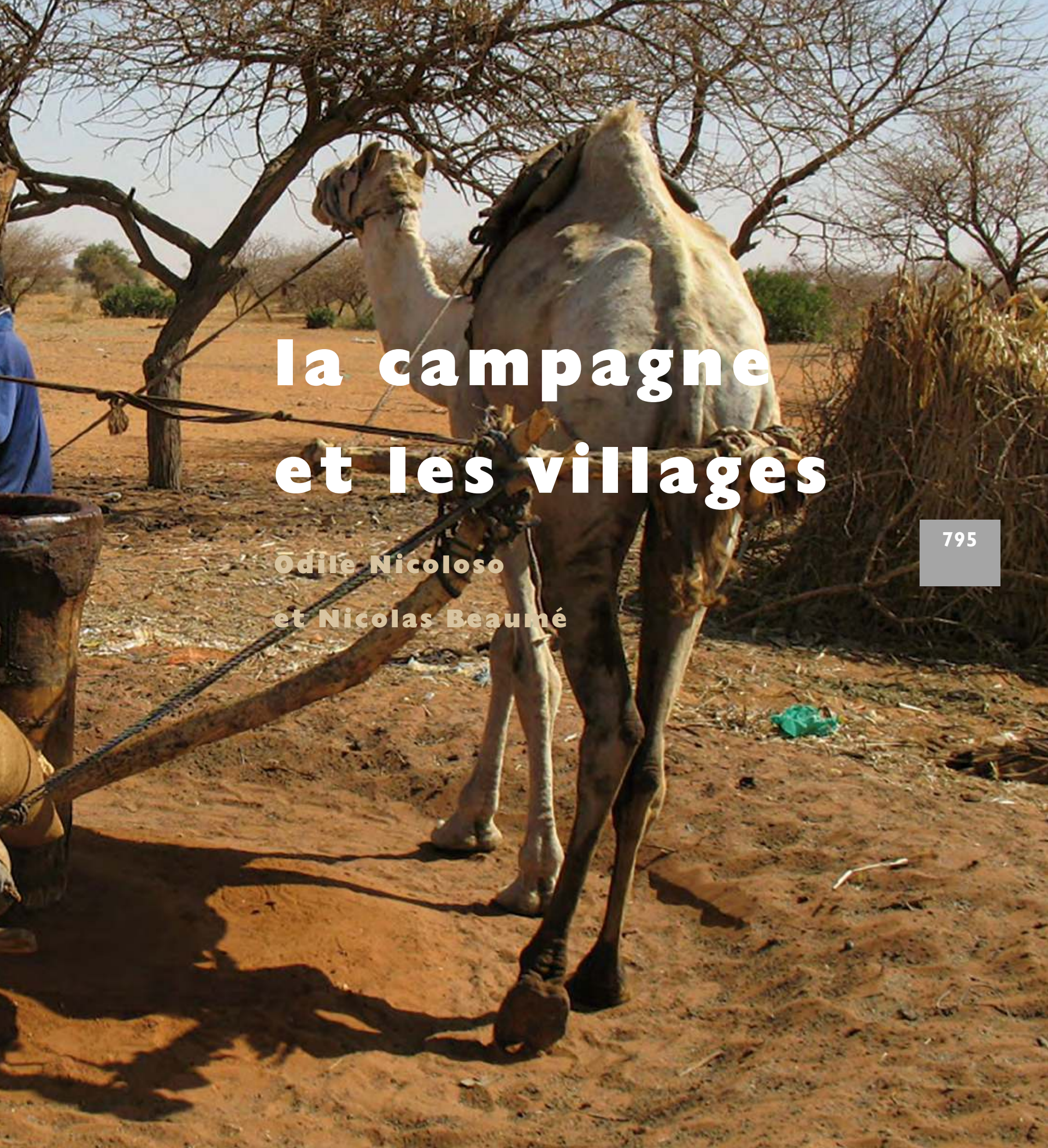





le Soudan

796

aujourd'hui
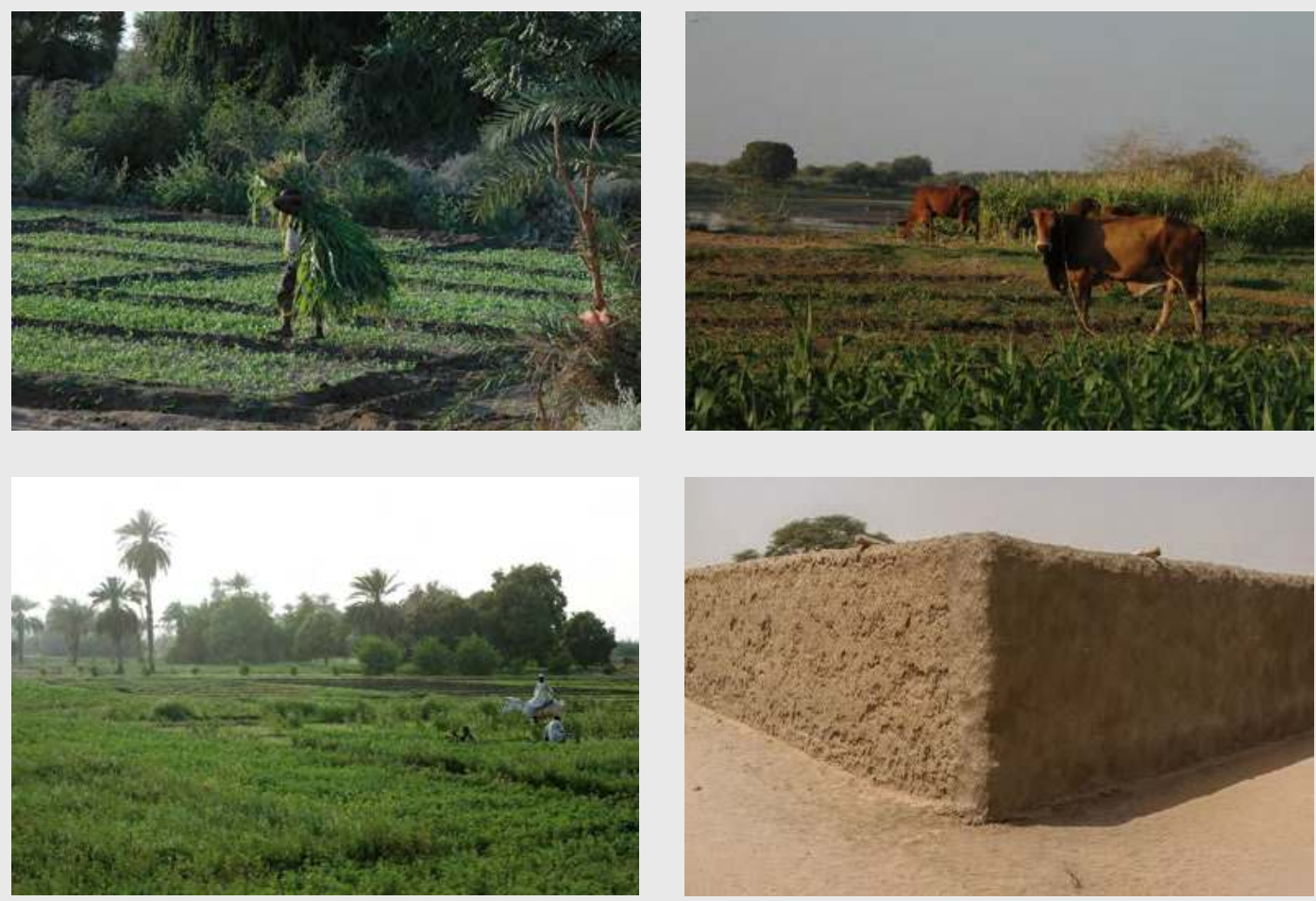

La campagne, le long du Nil, à Shendi (environ $200 \mathrm{~km}$ au nord-est de Khartoum), entre 2008 et 2013. 
La campagne soudanaise s'invite jusque dans la capitale, avec les champs inondables cultivés en pleine ville et l'île de Tuti restée (mais pour combien de temps?) un gros bourg rural au milieu de la cité. Les Soudanais conservent des liens forts avec leur village d'origine où vit parfois encore une partie de leur famille. Quand ils en ont les moyens, ils achètent une ferme pour y passer le week-end ou les fêtes et récolter leurs fruits et légumes.

Mais le Soudan est vaste et les campagnes, variées. L'archétype est la vallée du Nil, ruban de verdure très habité, dont le calme est seulement troublé par les pompes à eau qui irriguent les champs tous les cinquante mètres. Le paysage bucolique, si bien décrit par Jamal Mahjoub n'a pas changé depuis l'antiquité, même si l'électricité est désormais répandue et si les routes sont asphaltées. Aux abords des agglomérations, gros bourgs dotés d'un grand marché central, l'air est souvent pollué par les fumées âcres des fours qui transforment en briques le limon du Nil.

Au nord, de Khartoum jusqu'à la frontière égyptienne, c'est la Nubie traditionnelle: les murs de galous, sorte de torchis, ont des bandes horizontales d'environ soixante centimètres de hauteur, marques des «journées» de travail. Les villages très propres sont remarquables par les décorations extérieures sculptées et peintes sur les façades.
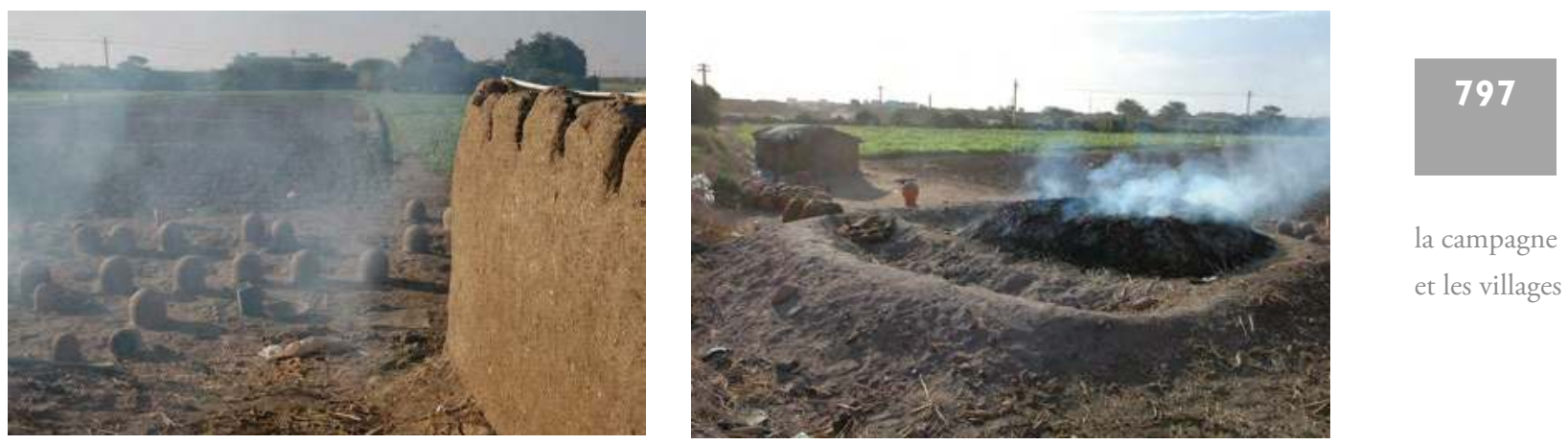

la campagne et les villages
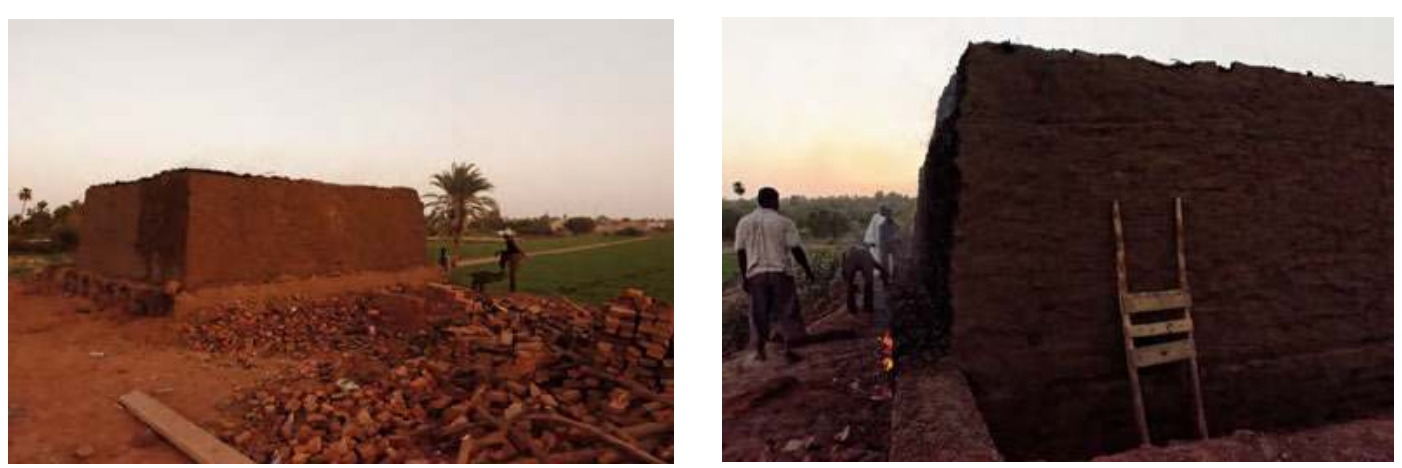

Poteries mises à sécher renversées et briqueterie le long de la rive du Nil à Shendi, en 2009 et 2012. 


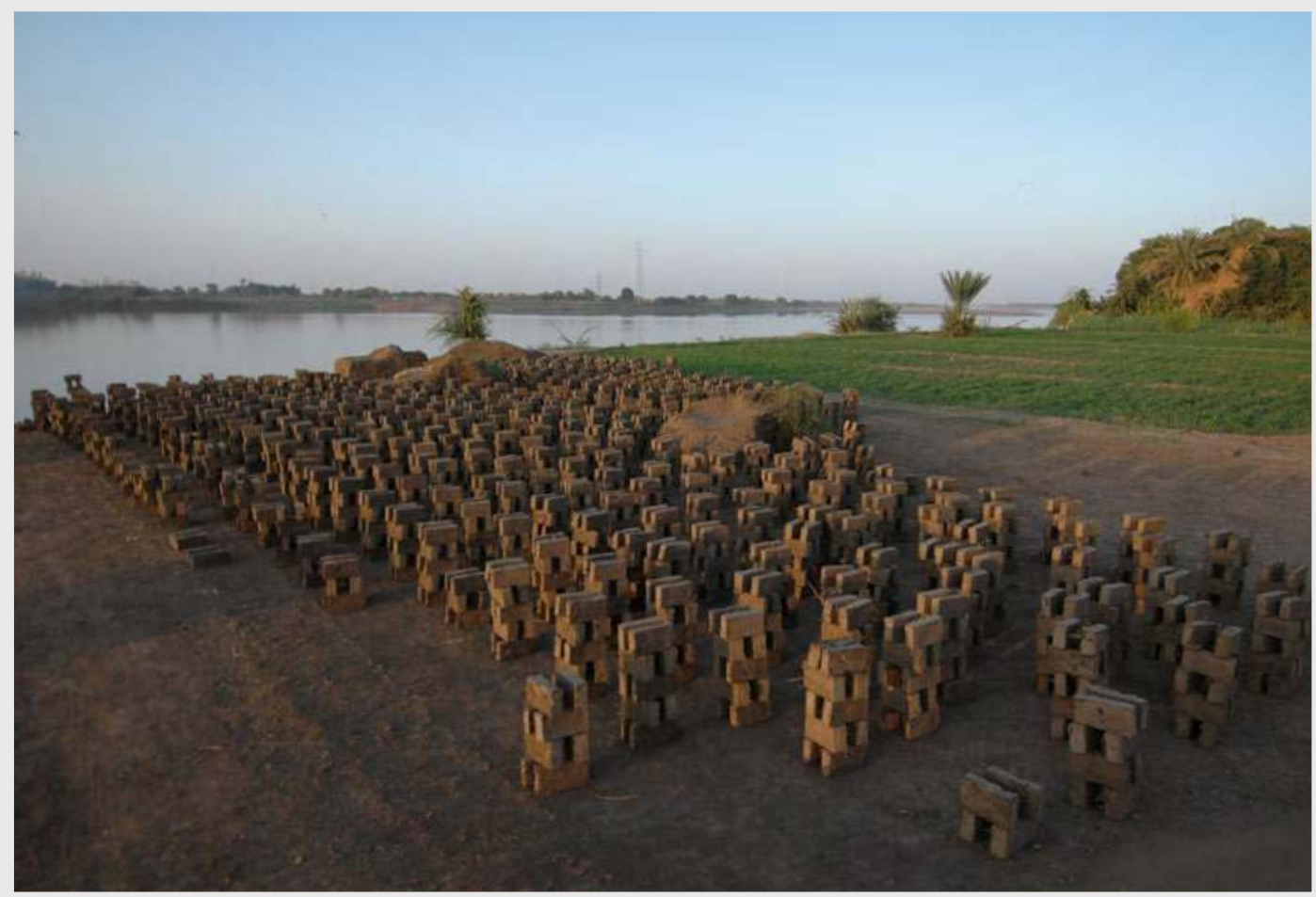

le Soudan

798

aujourd'hui
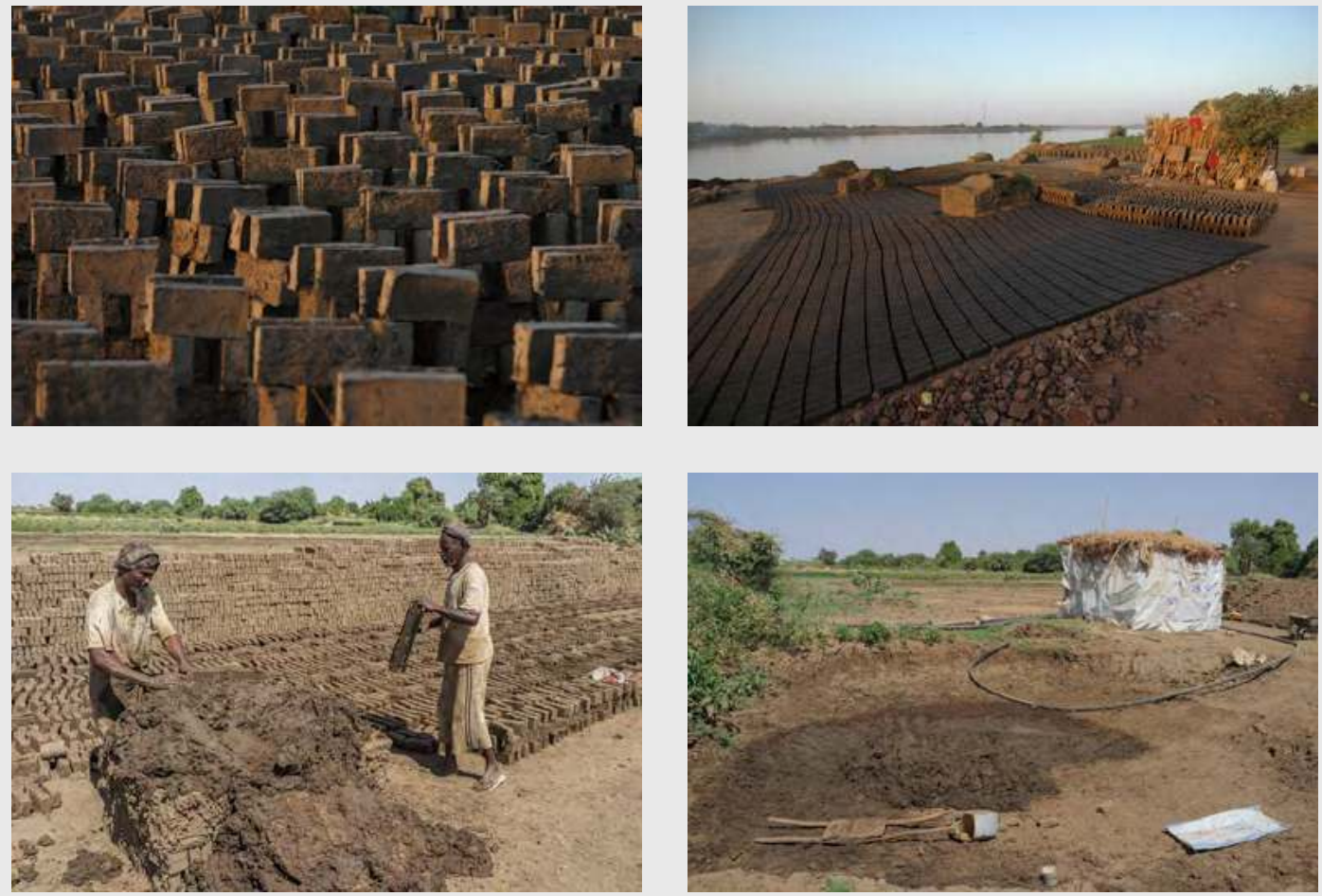

Briqueteries le long de la rive du Nil, à Shendi en 2009 et à Khartoum en 2013. 

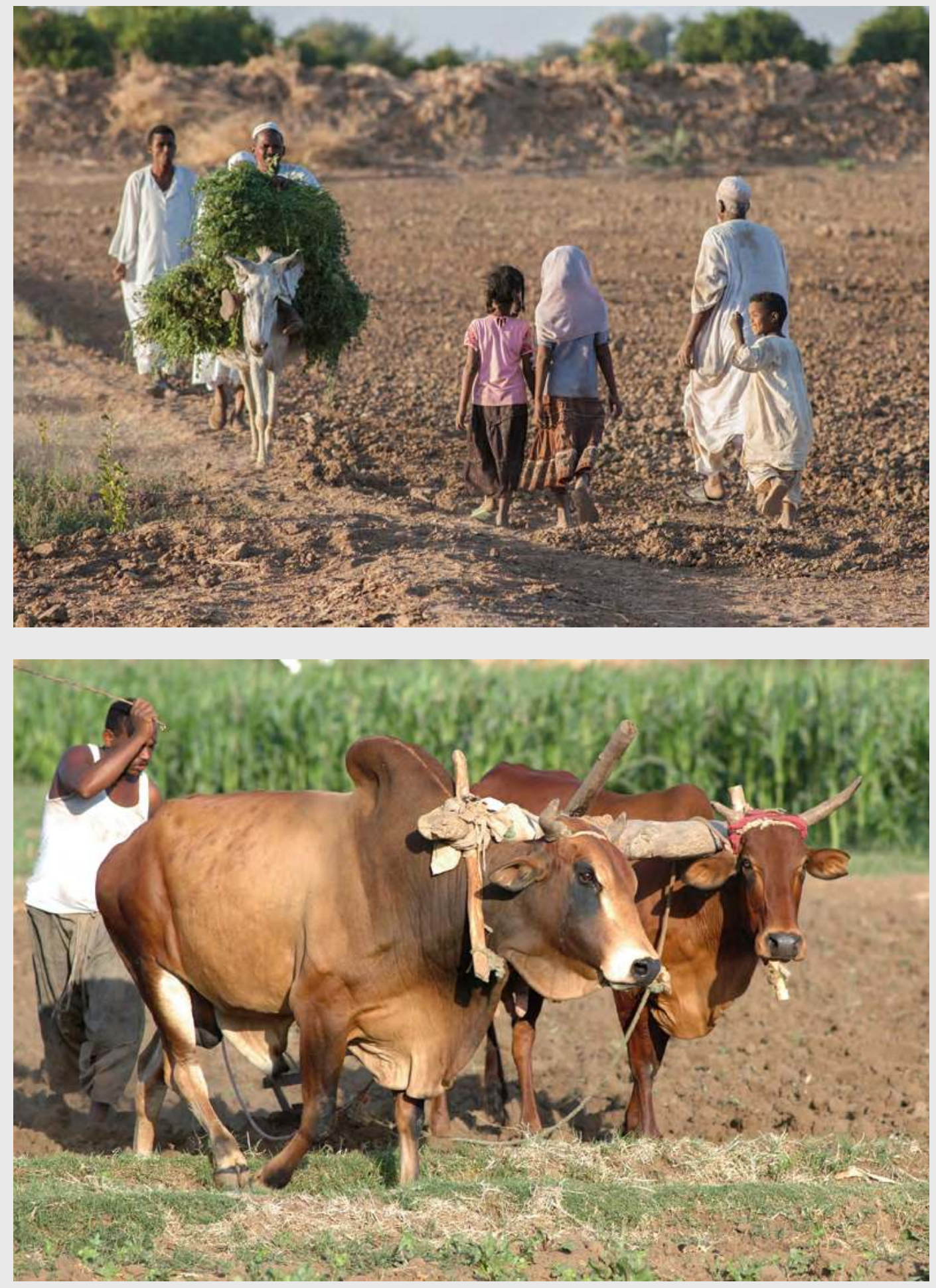


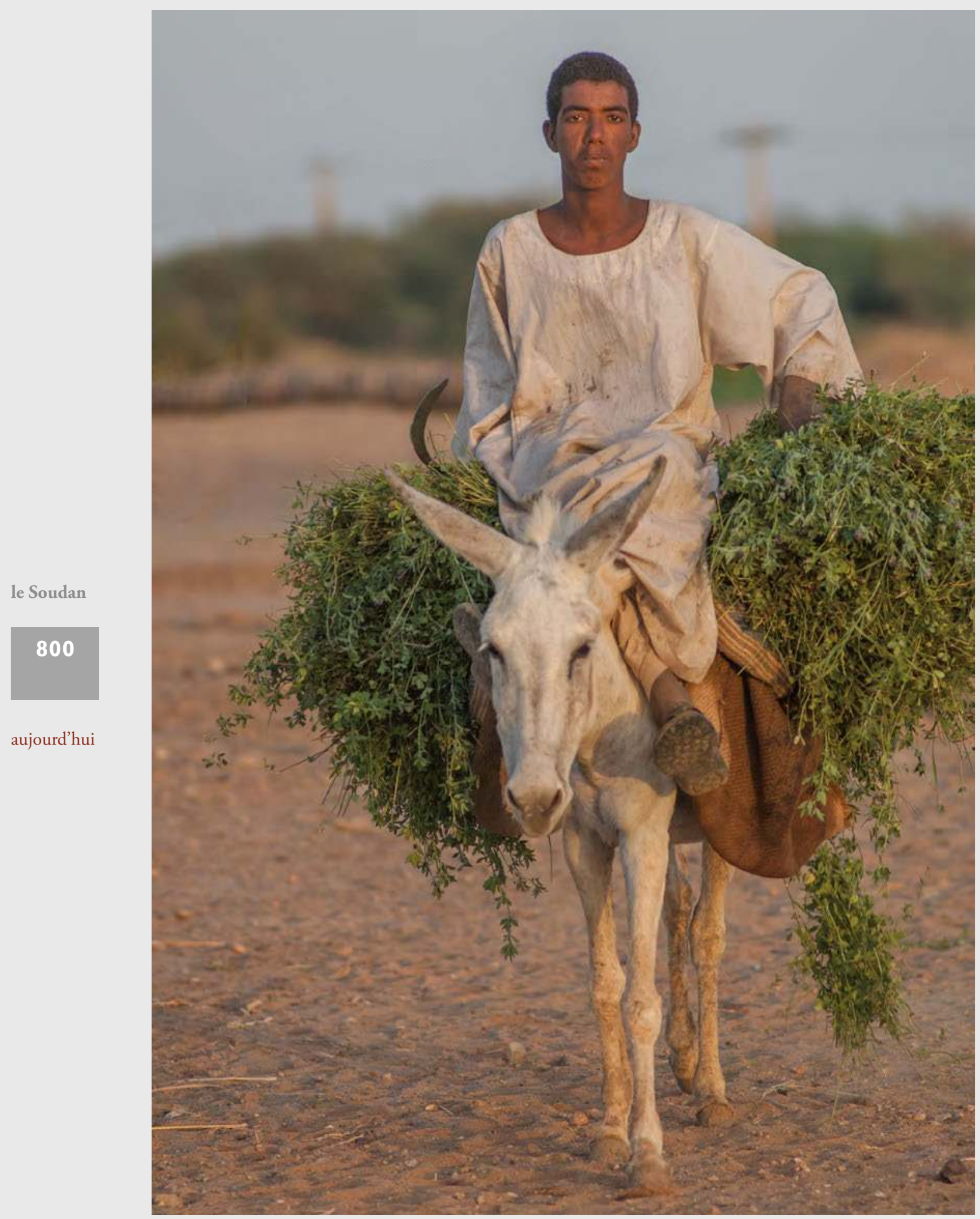



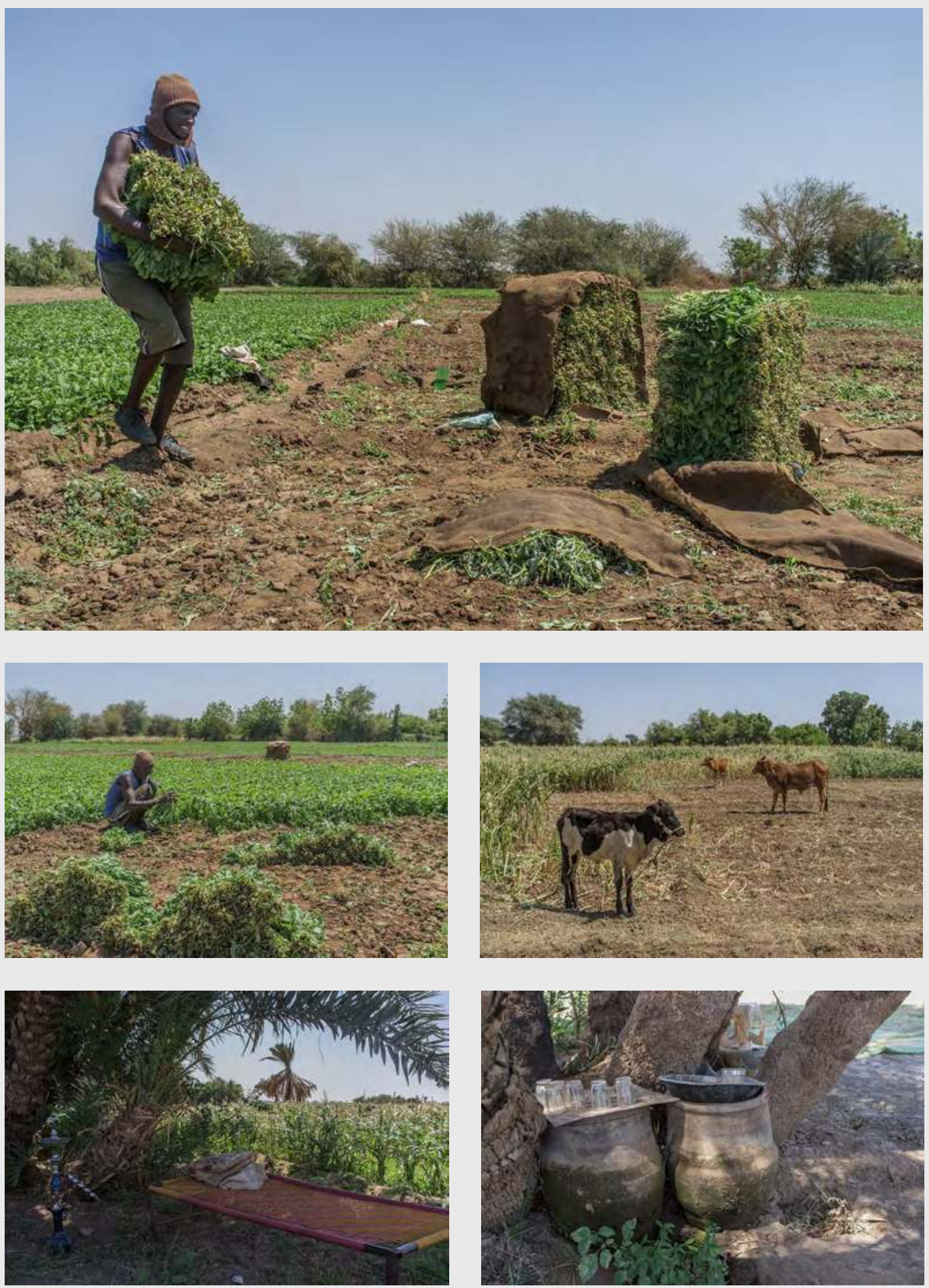

Shendi, en 2011 (à gauche).

Sur l'île de Tuti, point de rencontre du Nil Bleu et du Nil Blanc, en 2013 (ci-dessus). 


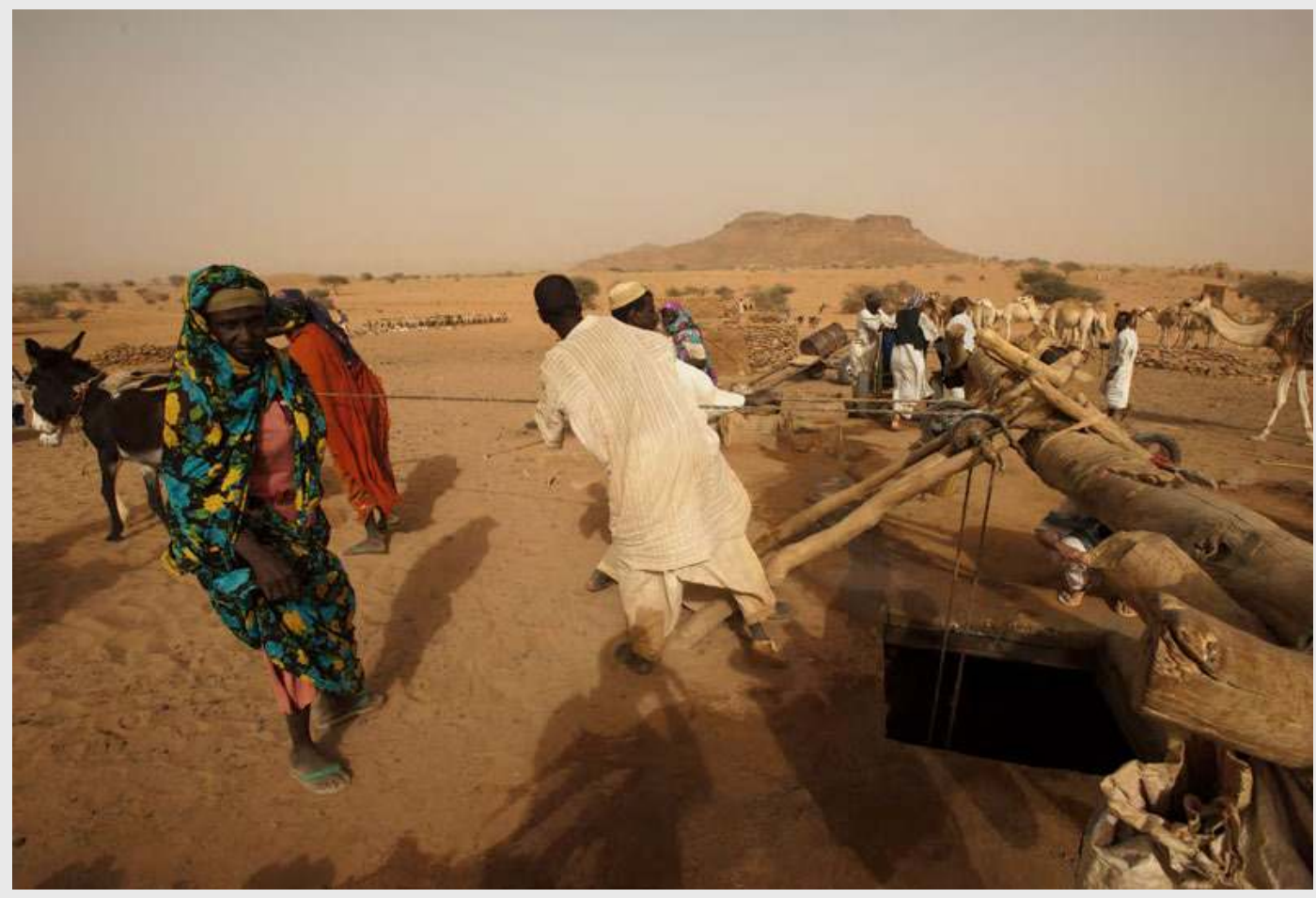

le Soudan

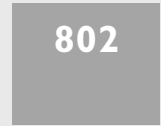

aujourd'hui
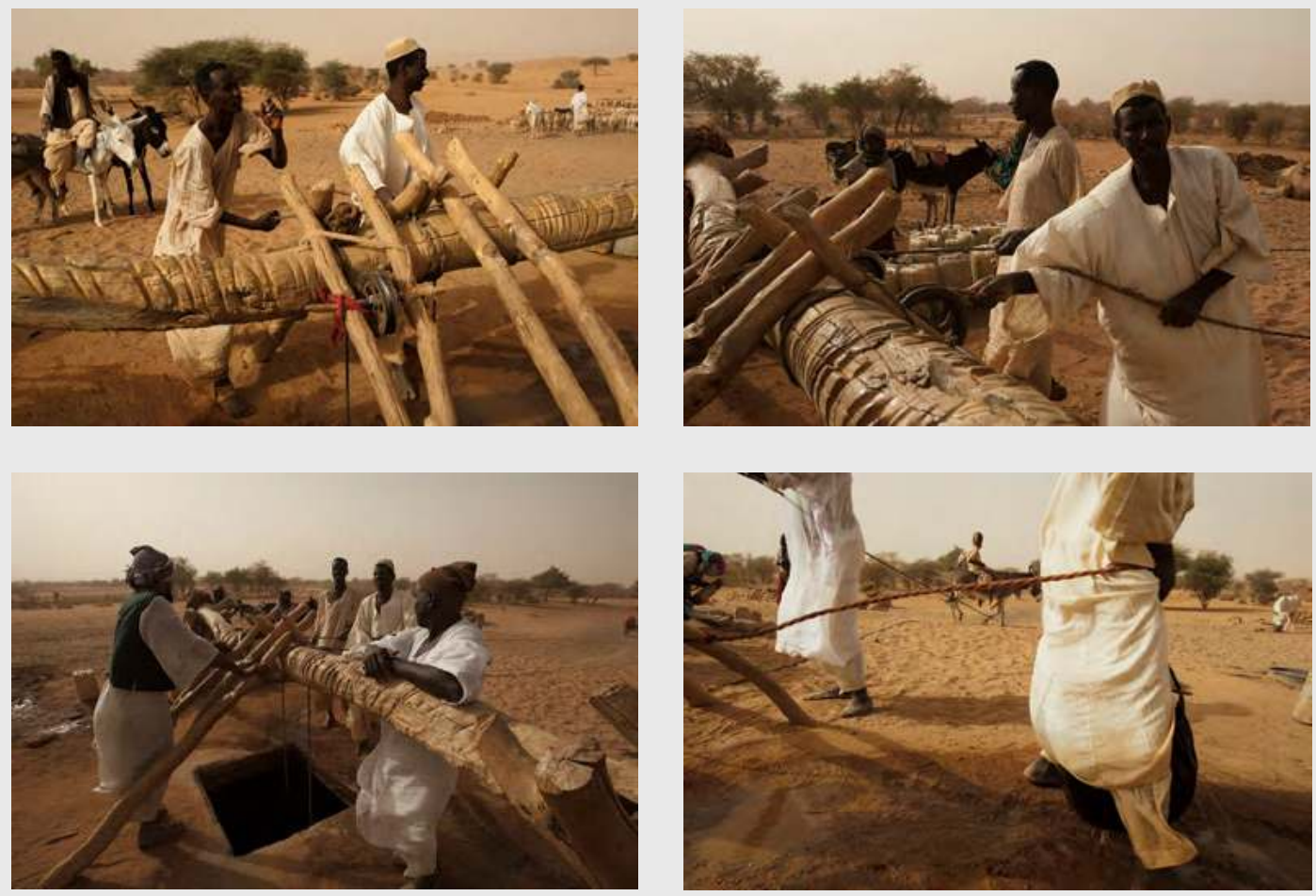

Le puits de Naga, aux environs de Musawwarat es-Sofra, en 2012. 


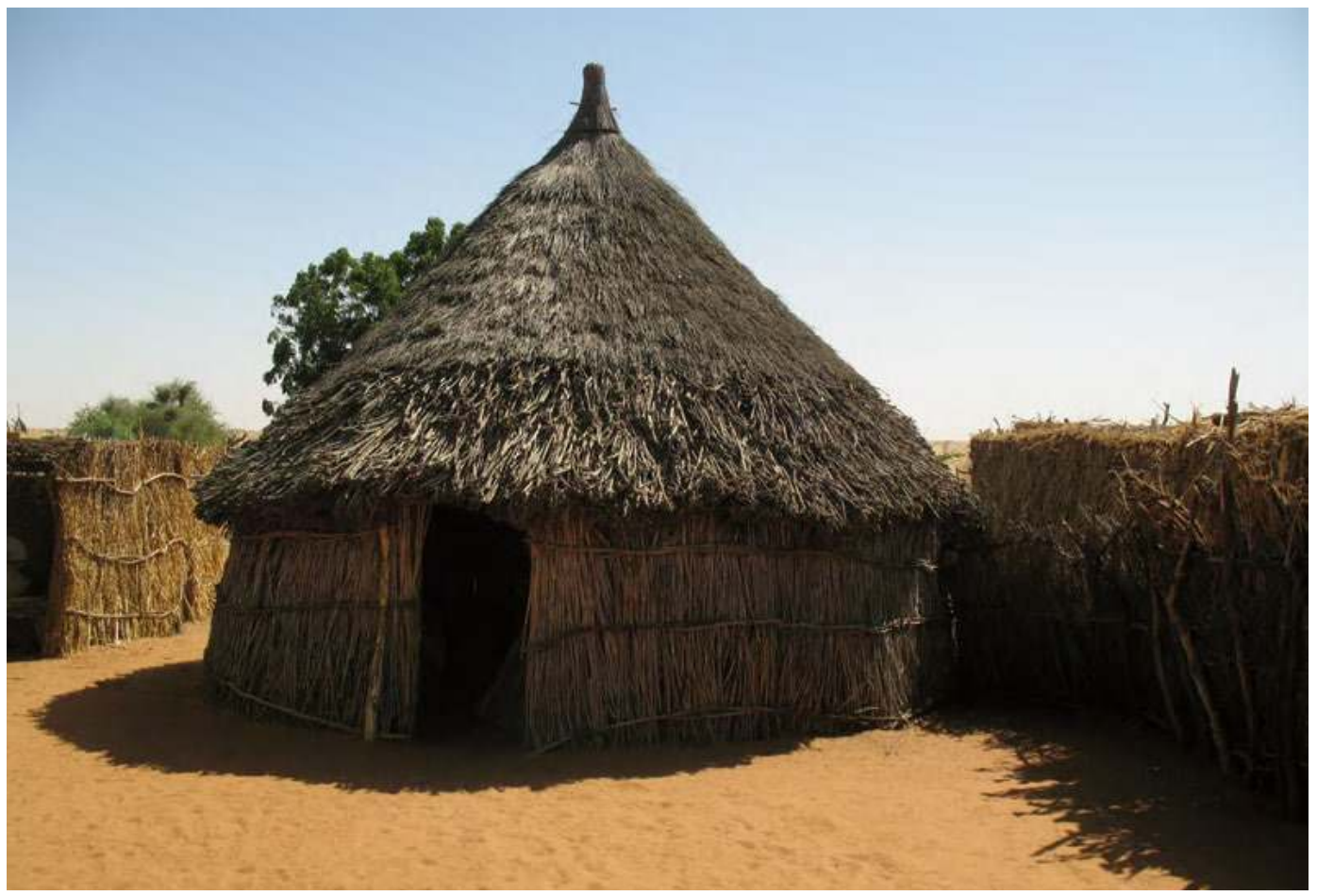

Hutte aux environs d'el-Obeid, 2008.

En dehors de la vallée, la vie est soumise aux pluviométries variables, du nord aride au sud plus arrosé. Aux vastes déserts caillouteux du nord et de l'est où vivent des populations très déshéritées d'éleveurs nomades, succèdent les zones plus arrosées du Darfour, à l'ouest, où le Gébel Marra joue le rôle de château d'eau. Cependant, la coexistence entre les éleveurs nomades Baggara (éleveurs de vaches) ou Abbala (éleveurs de chameaux) et les cultivateurs sédentaires a toujours été très compliquée, jusqu’à dégénérer en conflit violent depuis le début des années 2000.

Le Kordofan, est le royaume du baobab (tabaldi) et de l'acacia qui produit la gomme arabique. Mais le massif montagneux des Monts Nouba, où se côtoient de nombreuses tribus aux dialectes différents et qu’ont immortalisé les photographies de Leni Riefenstahl, est, lui aussi, une zone de conflits.

Enfin, entre les deux Nils (dans la Gezira, l'île) et dans les vastes plaines de Gedaref et Kassala jusqu'aux confins de l'Éthiopie et de l'Érythrée, s'étend le grenier du Soudan où de gros propriétaires terriens et des entreprises privées récoltent céréales et canne à sucre dans les zones irriguées. La main-d'œuvre paysanne est souvent venue d'ailleurs: des régions déshéritées du Soudan, du Soudan du Sud et d'Érythrée, mais aussi d'Afrique de l'Ouest qui a laissé au Soudan, du temps du pèlerinage par voie terrestre, plusieurs millions de personnes constituant le groupe des Fallatas 


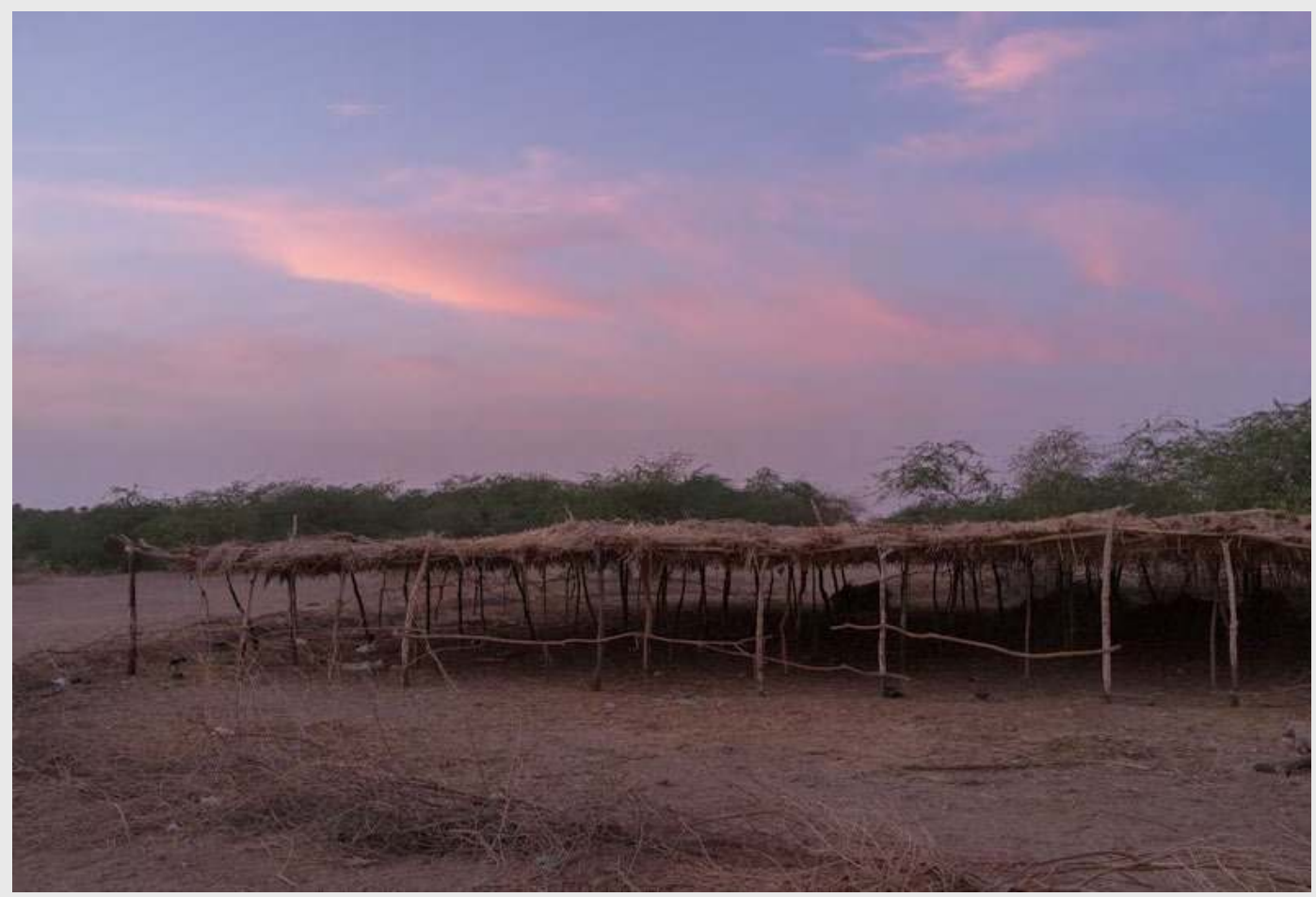

le Soudan

804

aujourd'hui
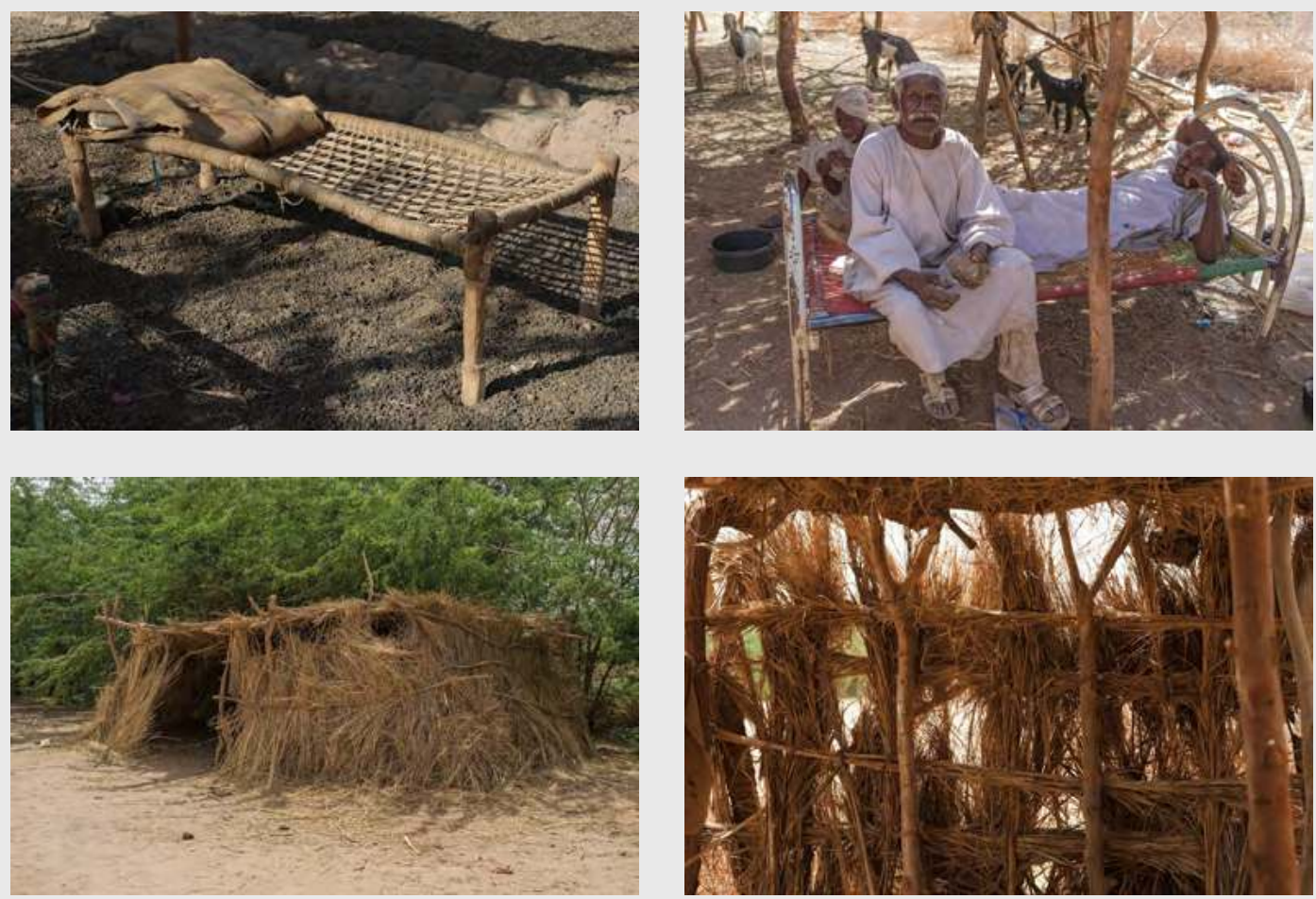

Sur le site de Mouweis, aux environs de Shendi, en 2010 et 2013 : l'okkuba;

un engareb en bois et sa déclinaison "moderne» en fer, résistante aux termites; un abri rustique. 

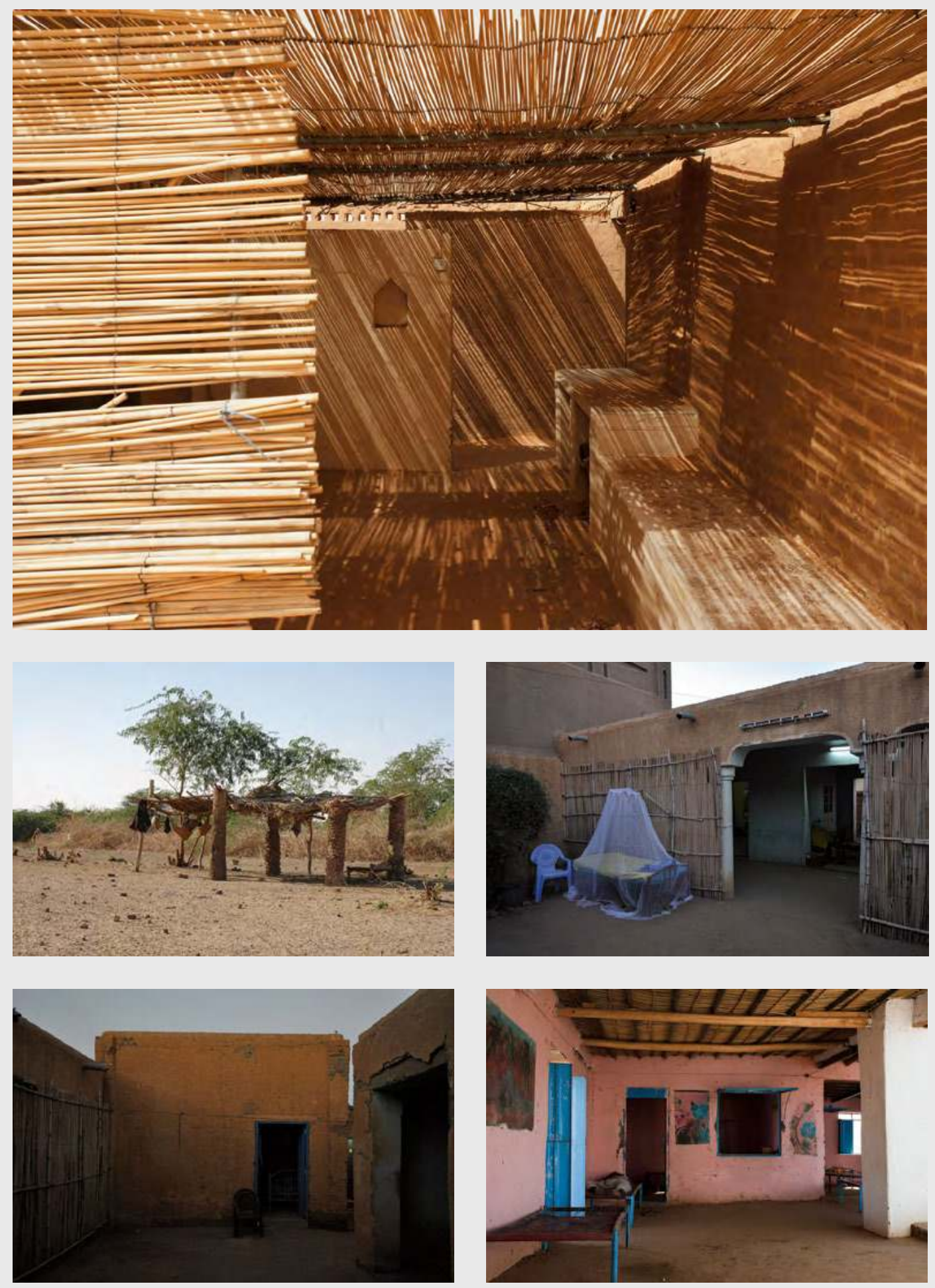

La «maison de fouilles» allemande à Musawwarat, construite d'après un modèle "traditionnel » (2012); abri rustique et cour d'une maison de Shendi (2010); relais « routier » aux environs de Méroé (2011). 
le Soudan

806

aujourd'hui

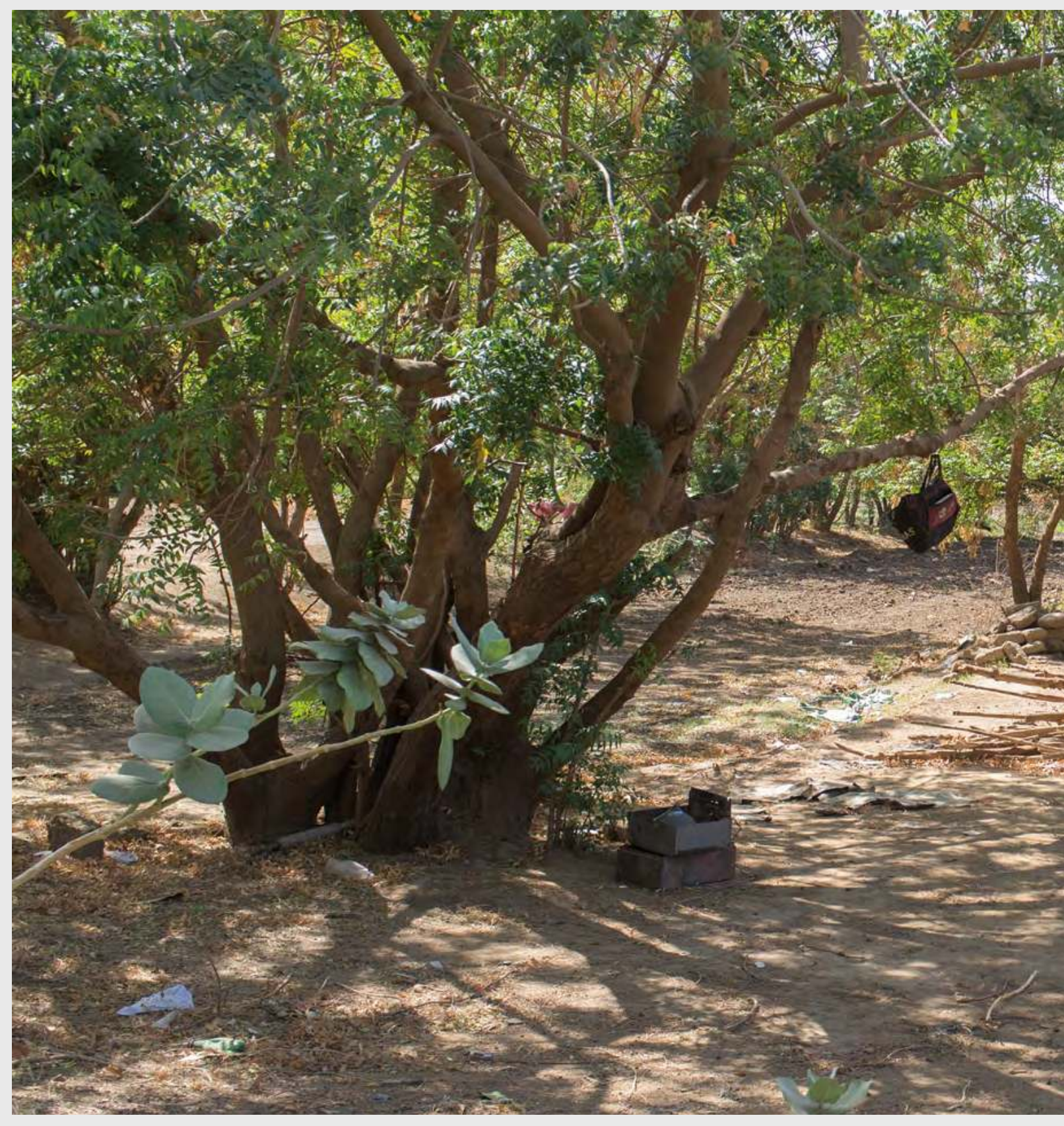

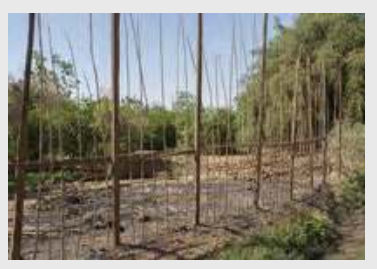

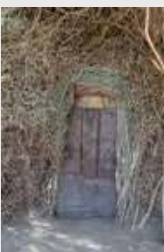

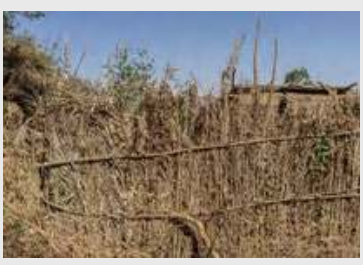

Île de Tuti, à Khartoum, en 2013. 


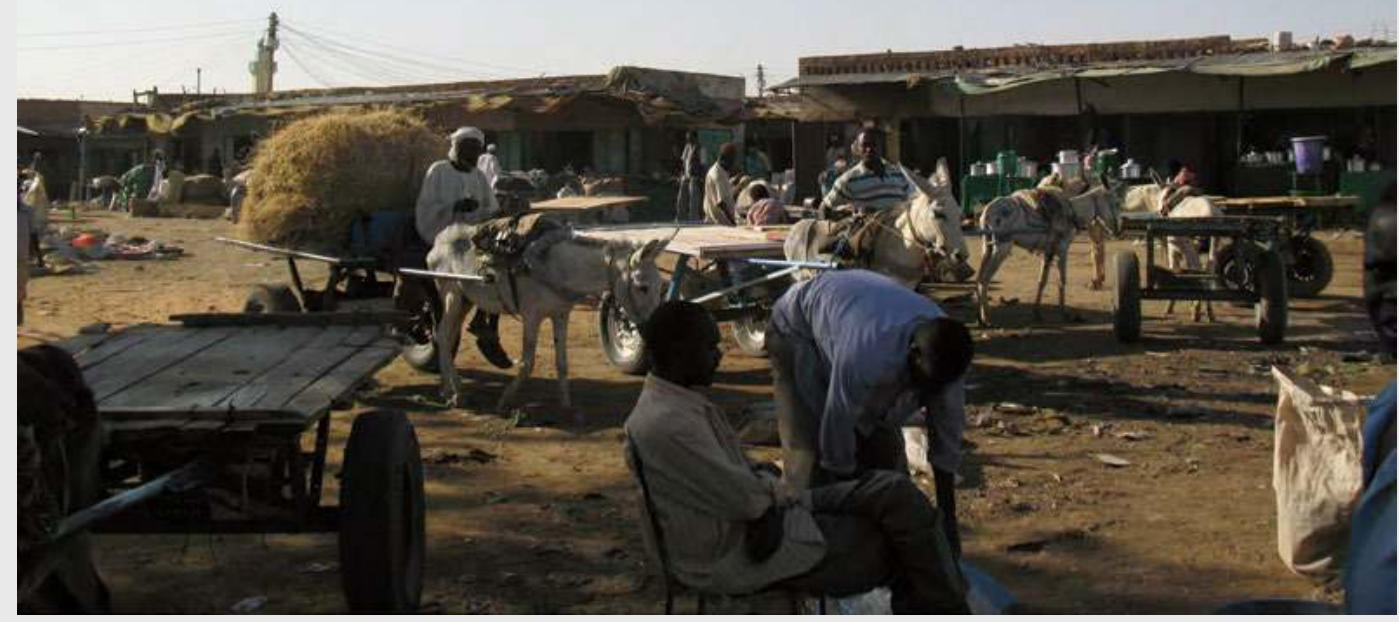

le Soudan

808

aujourd'hui
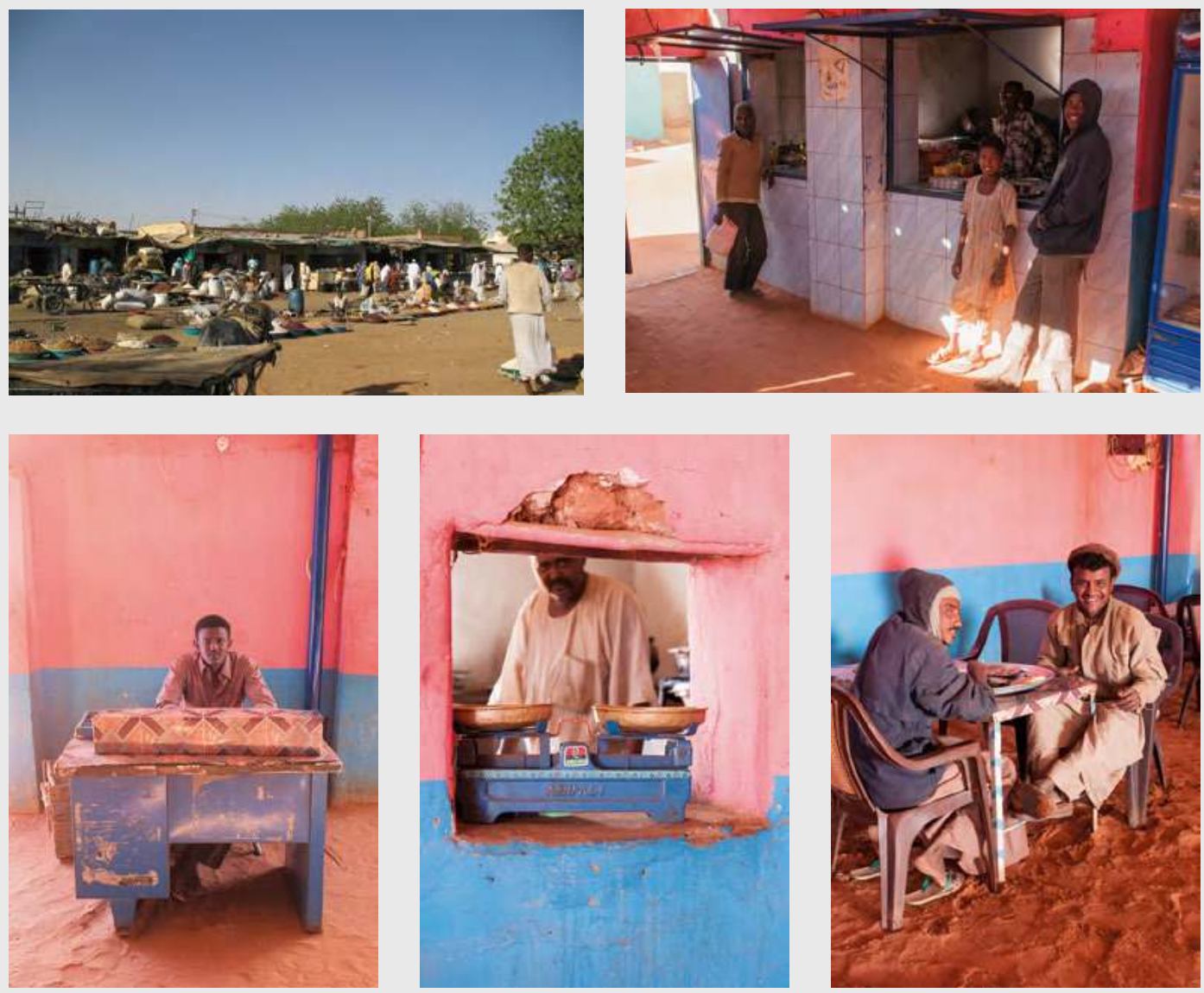

El-Obeïd (45o km au sud-ouest de Khartoum) et restaurant aux environs de Karima (350 km au nord), en 2012. 

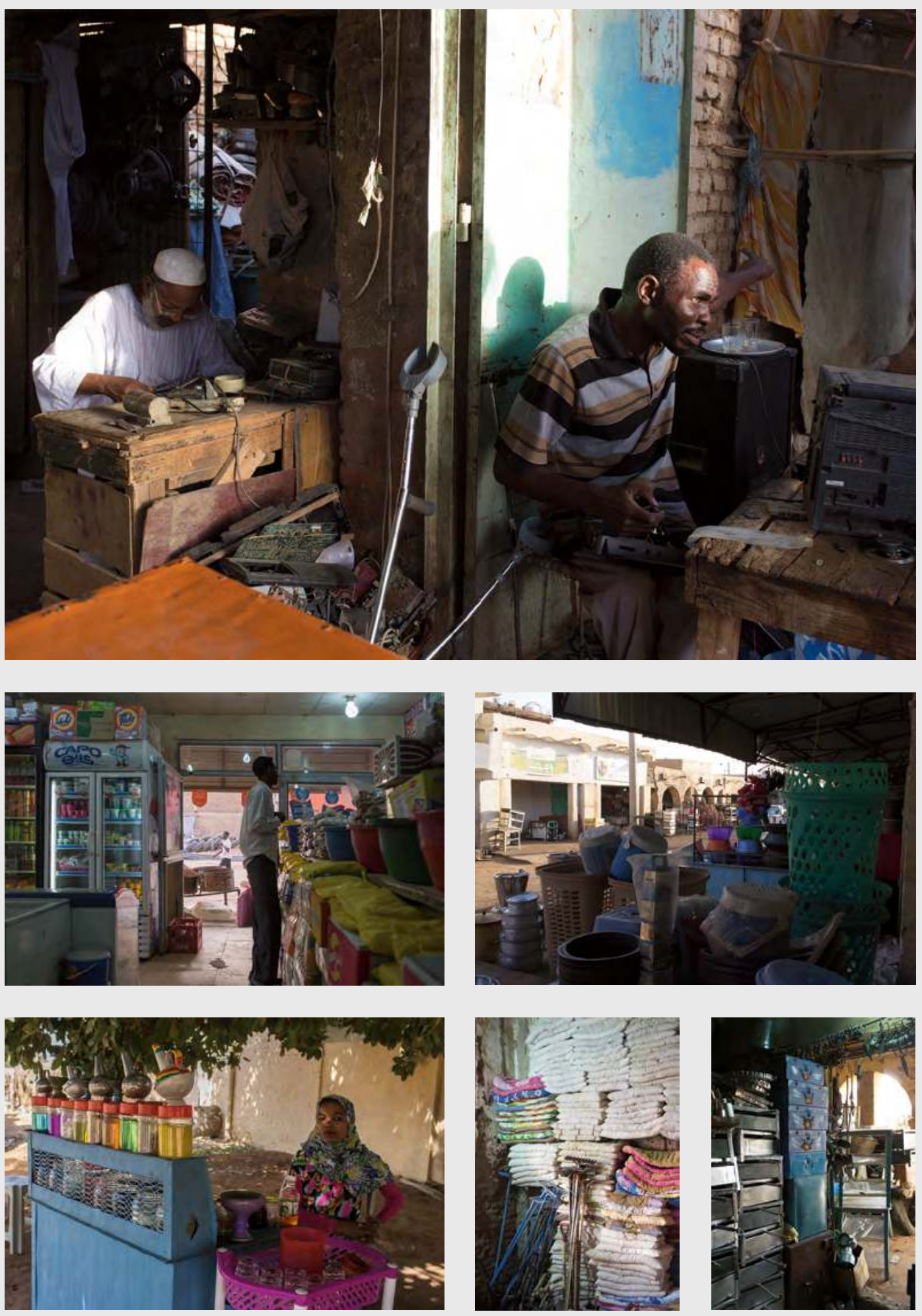

Artisans, épicerie, magasins et sitta chay (sett eš-šay, littéralement "dame du thé») à Shendi, en 2013. 


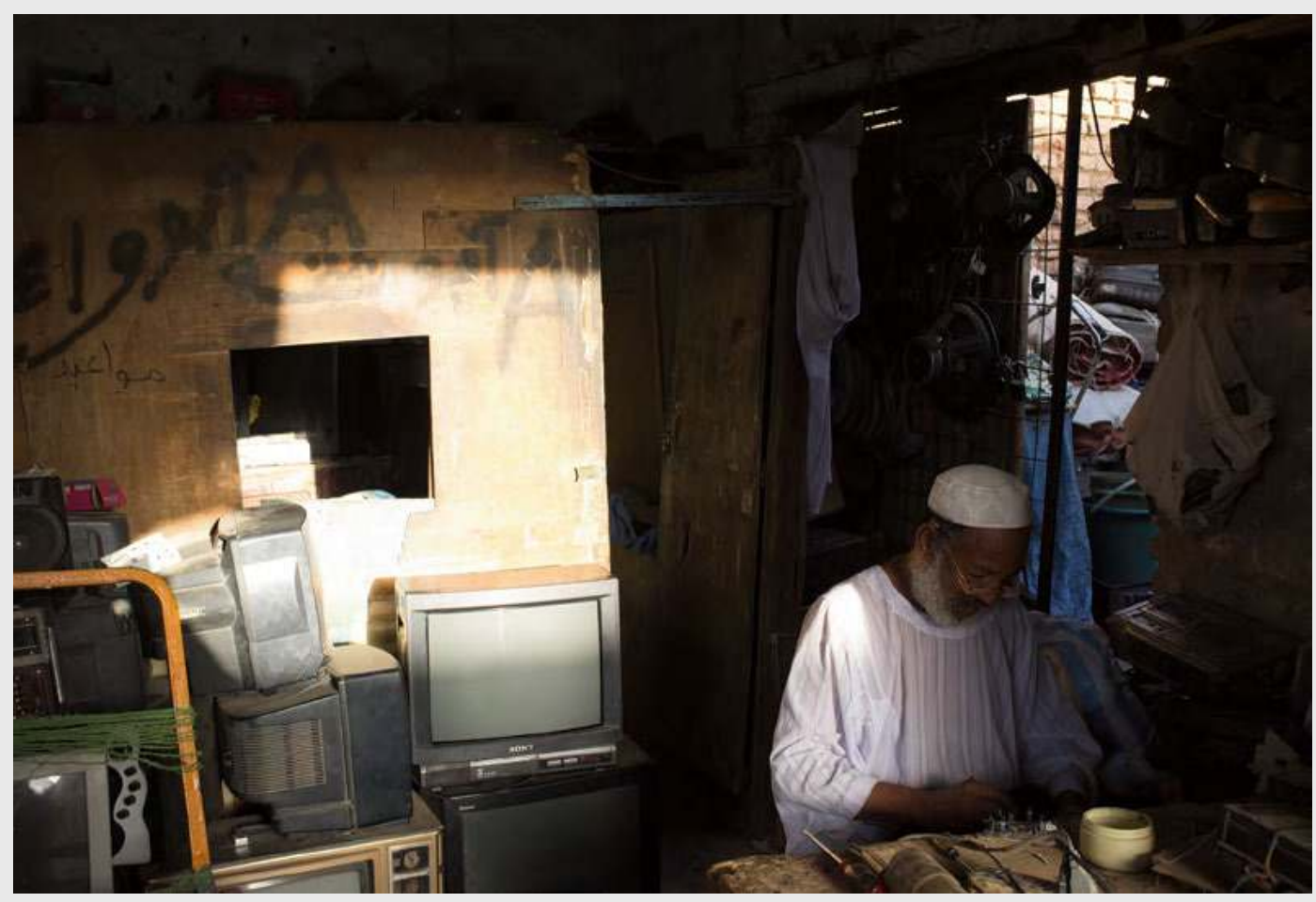

le Soudan

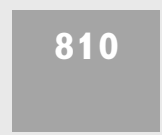

aujourd'hui
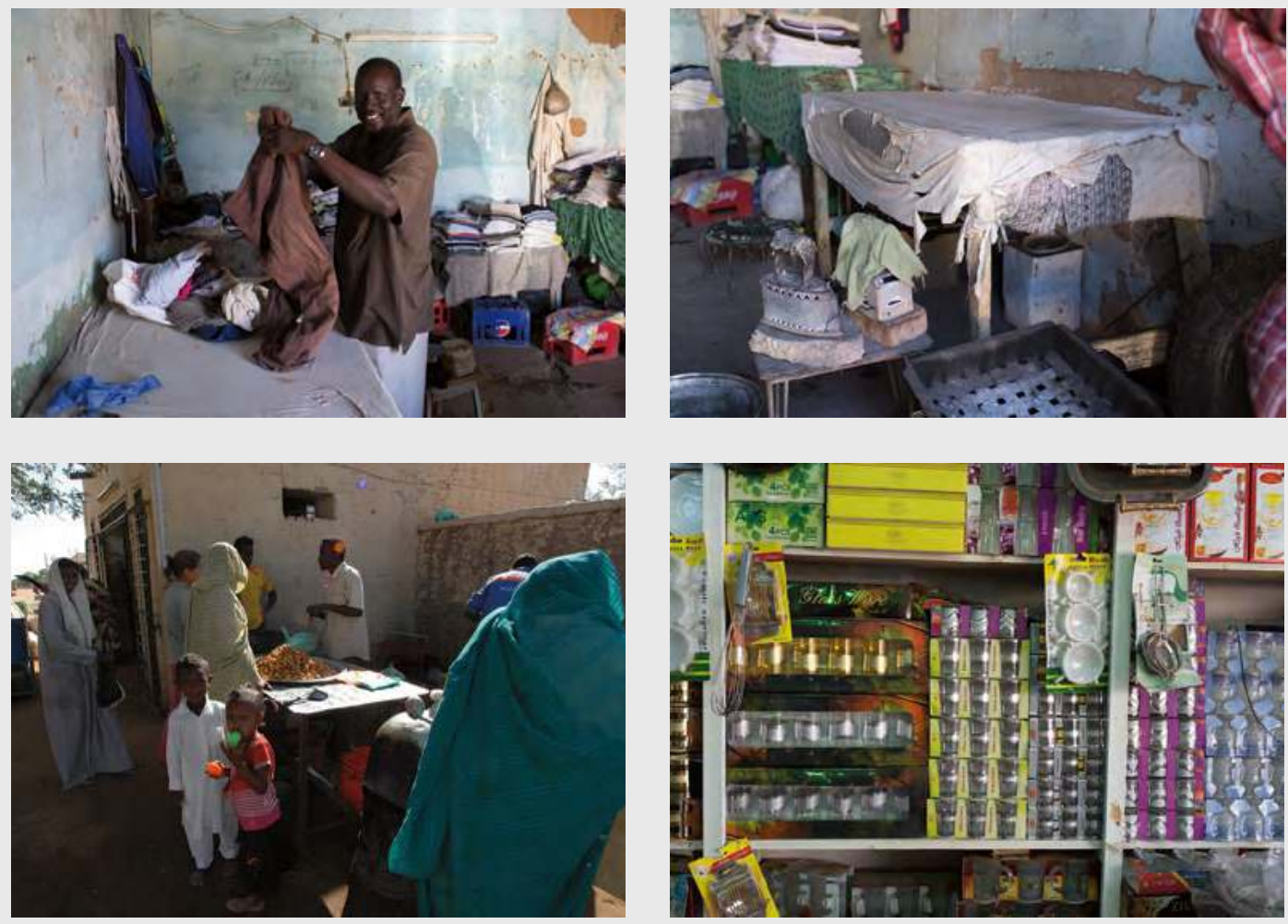

Réparateurs de télévision et d'électroménager, repasseurs et boutiques de rue à Shendi, en 2013. 

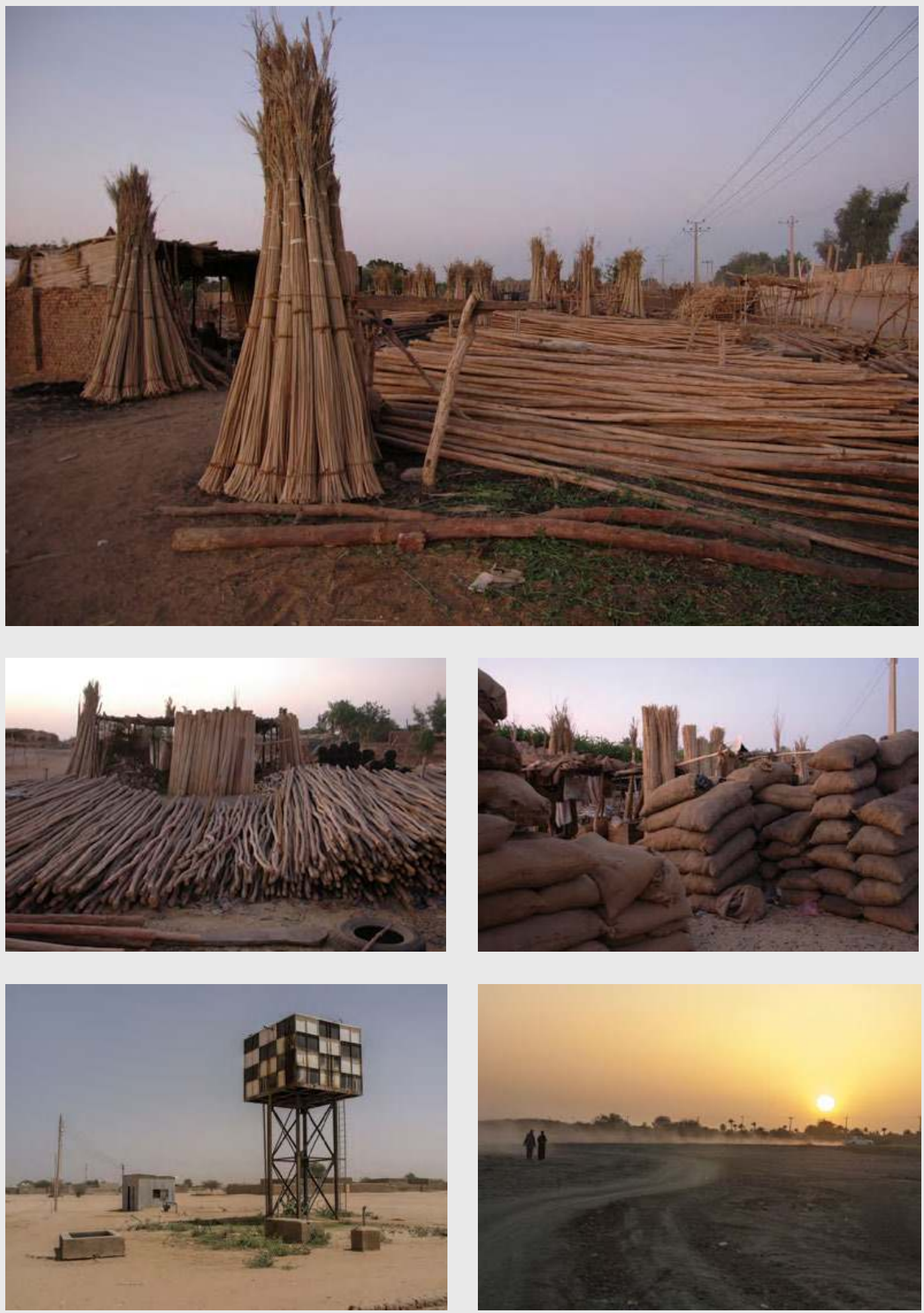

la campagne et les villages

Quartier des vendeurs de bois et de charbon, château d'eau et abords de la ville de Shendi, en 2009 et 2013. 


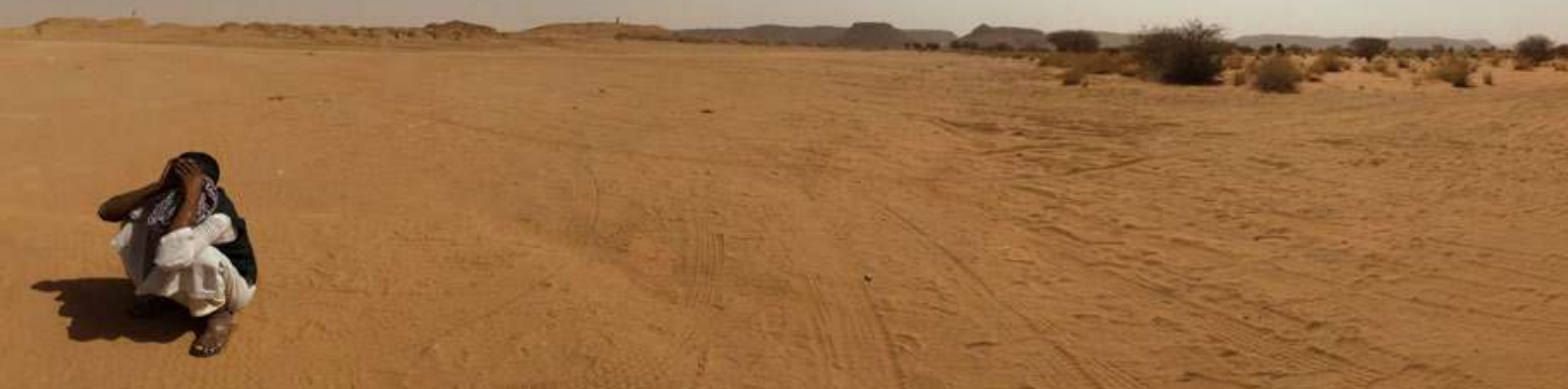

le Soudan

812
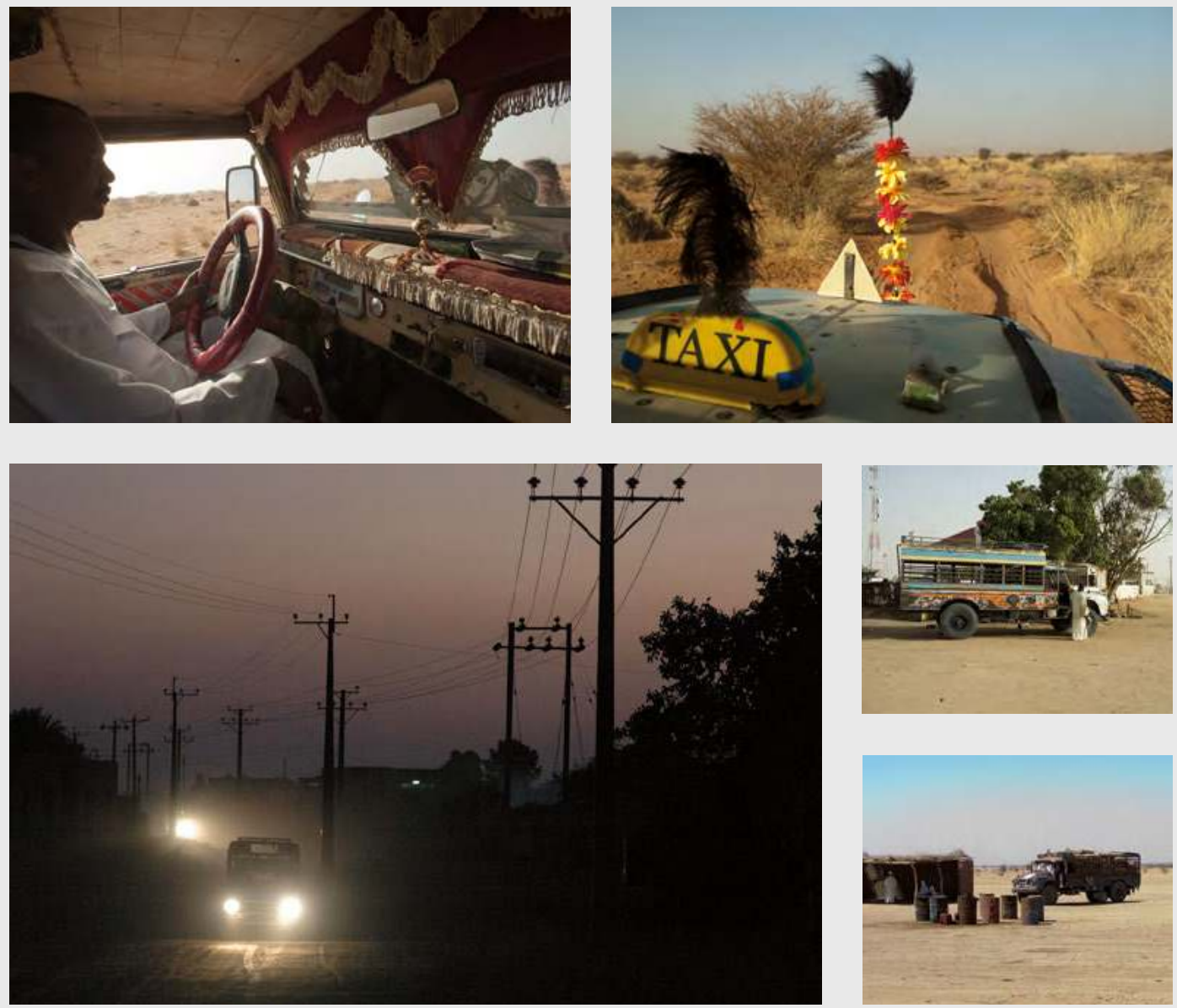

aujourd'hui

Taxi baladi vers Musawwarat, «Bedford» et transports locaux, entre 2010 et 2012.

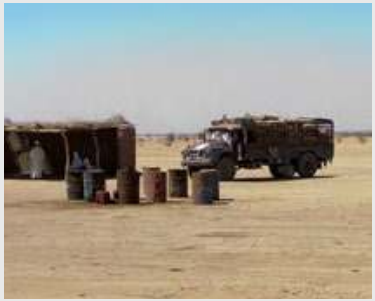

Taxi baladi vers Musawwarat, "Bedford» et transports locaux, entre 2010 et 2012. 

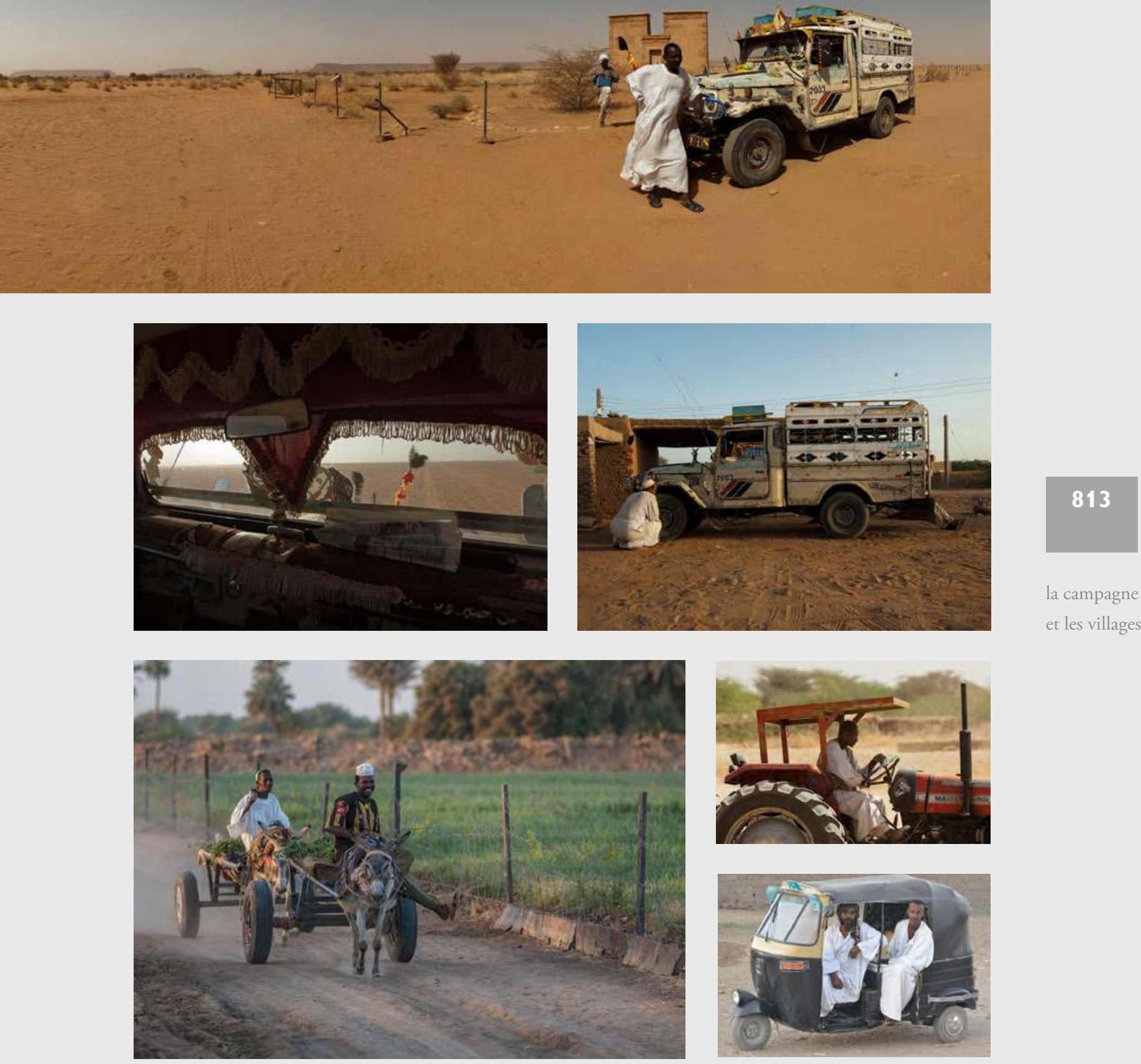

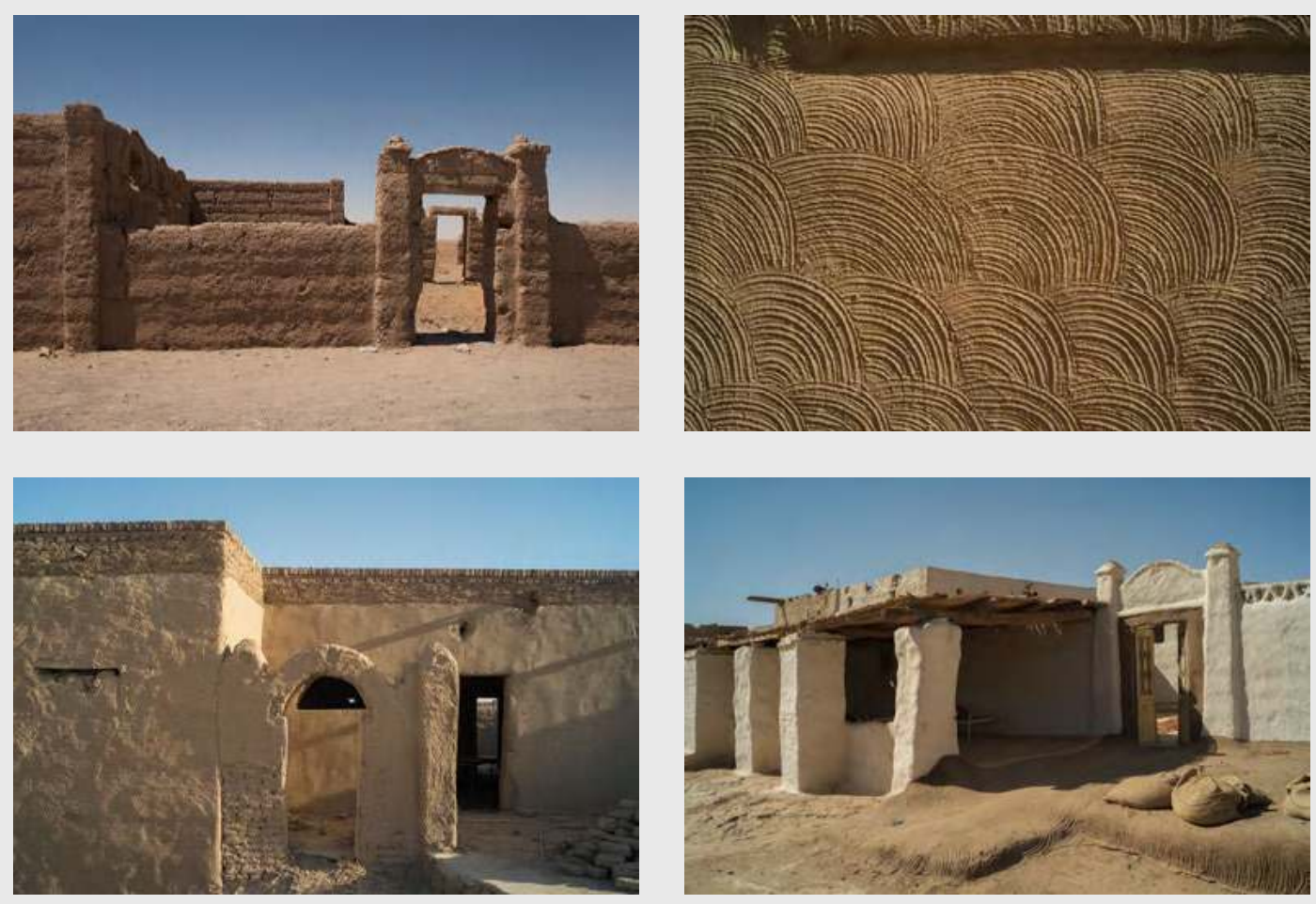

le Soudan
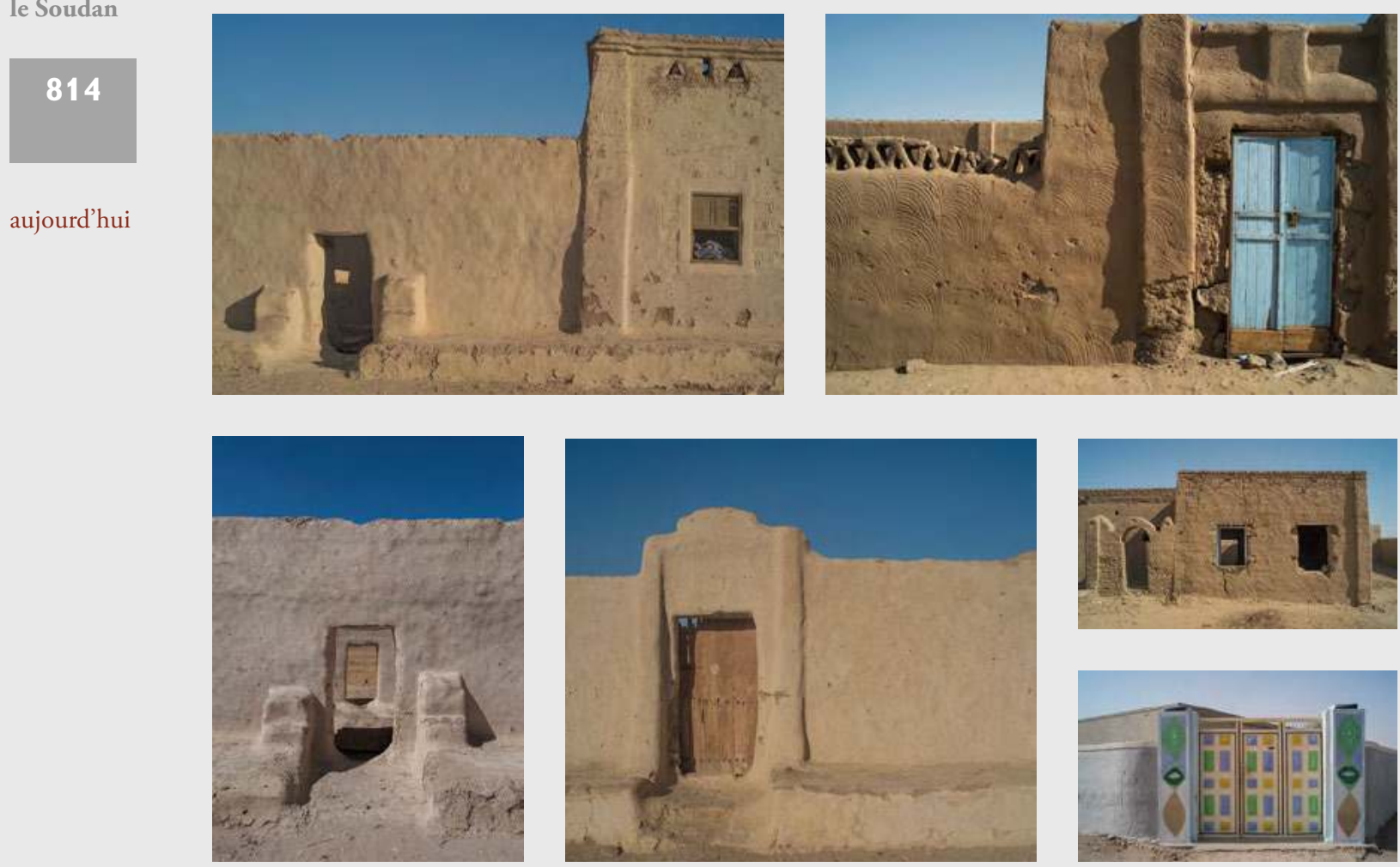

Île de Saï, nord du Soudan (à environ à 650 km «à vol d'oiseau » de Khartoum), octobre 2015. 

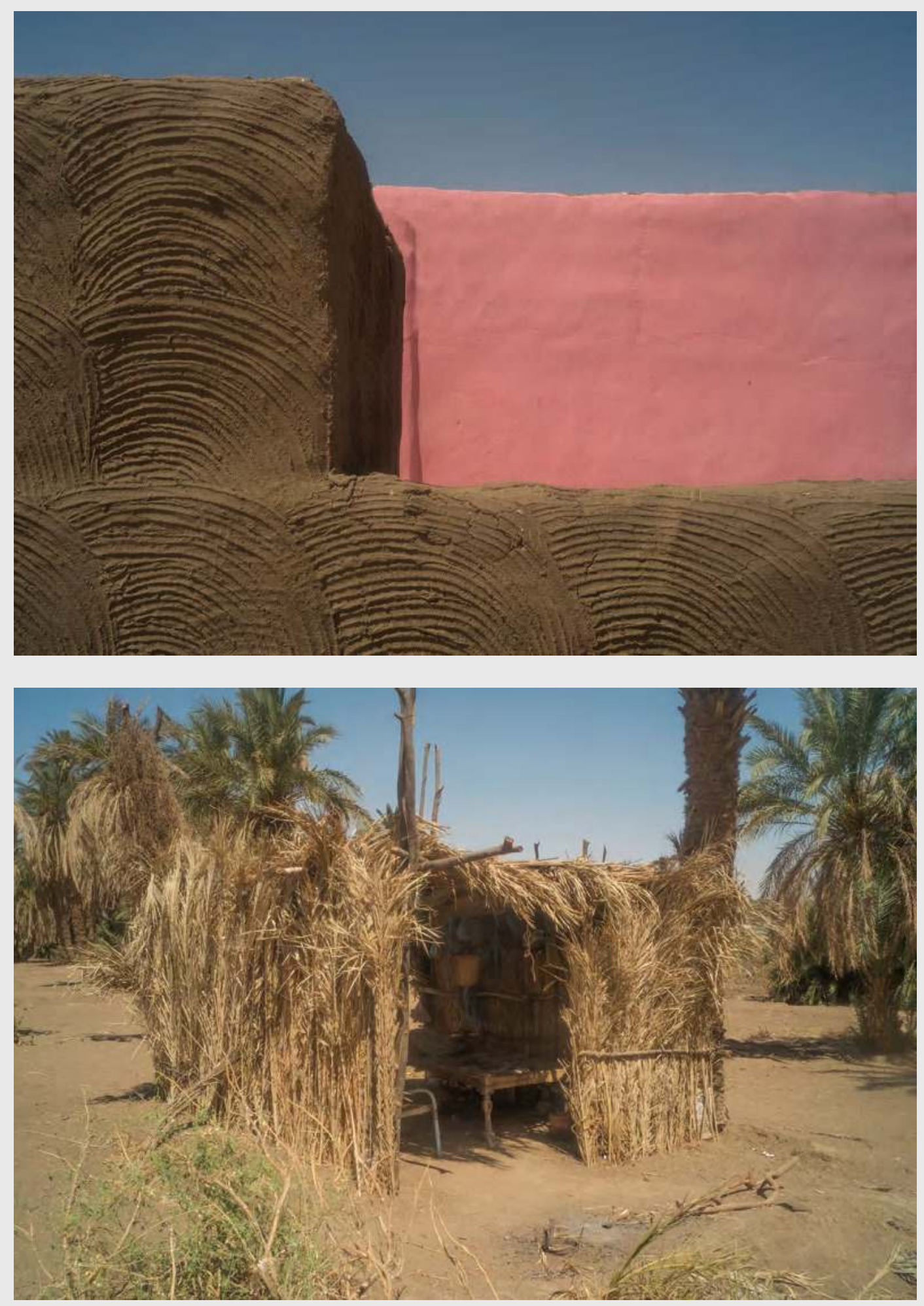

la campagne et les villages 


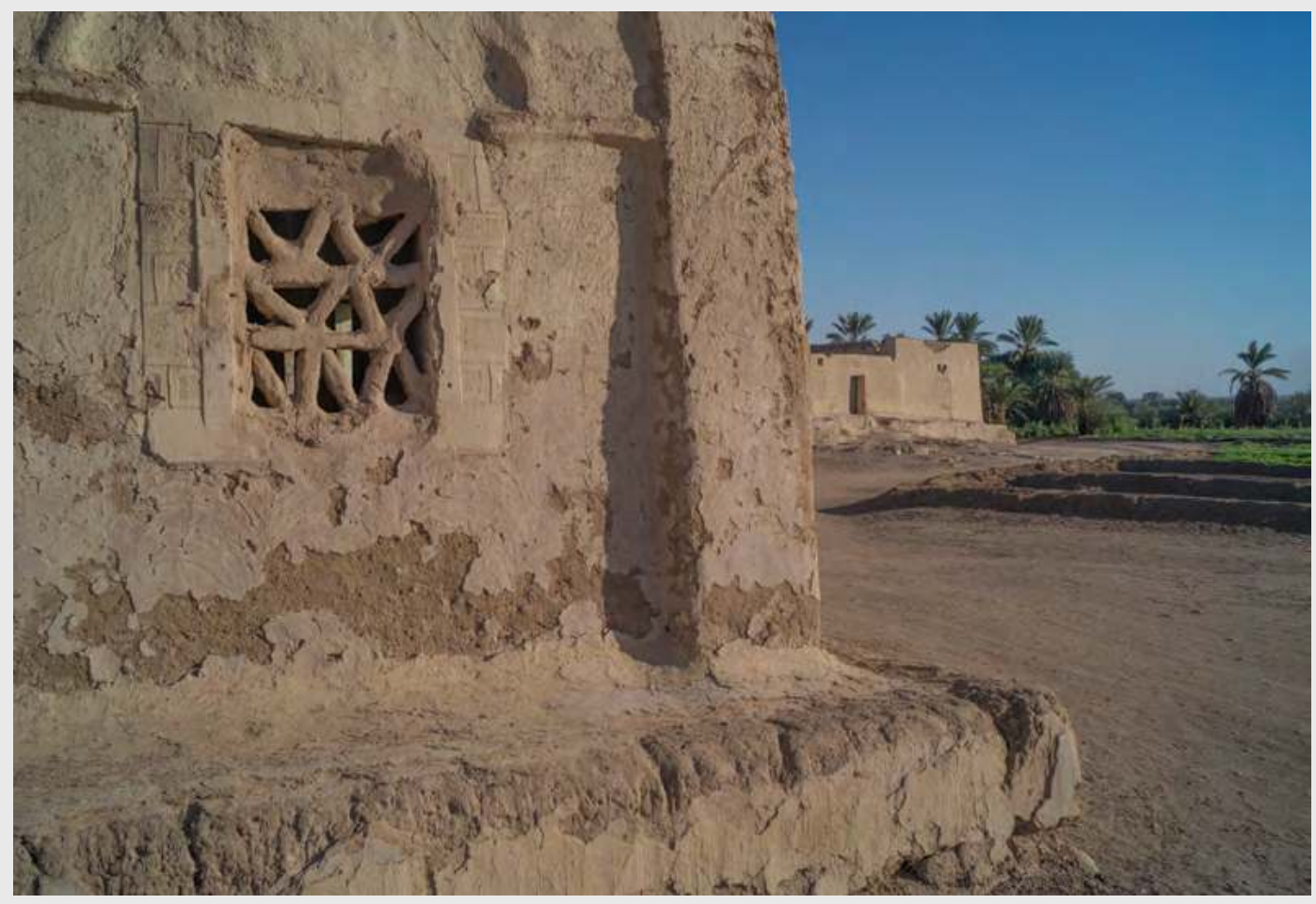

le Soudan

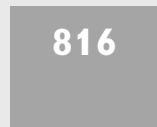

aujourd'hui
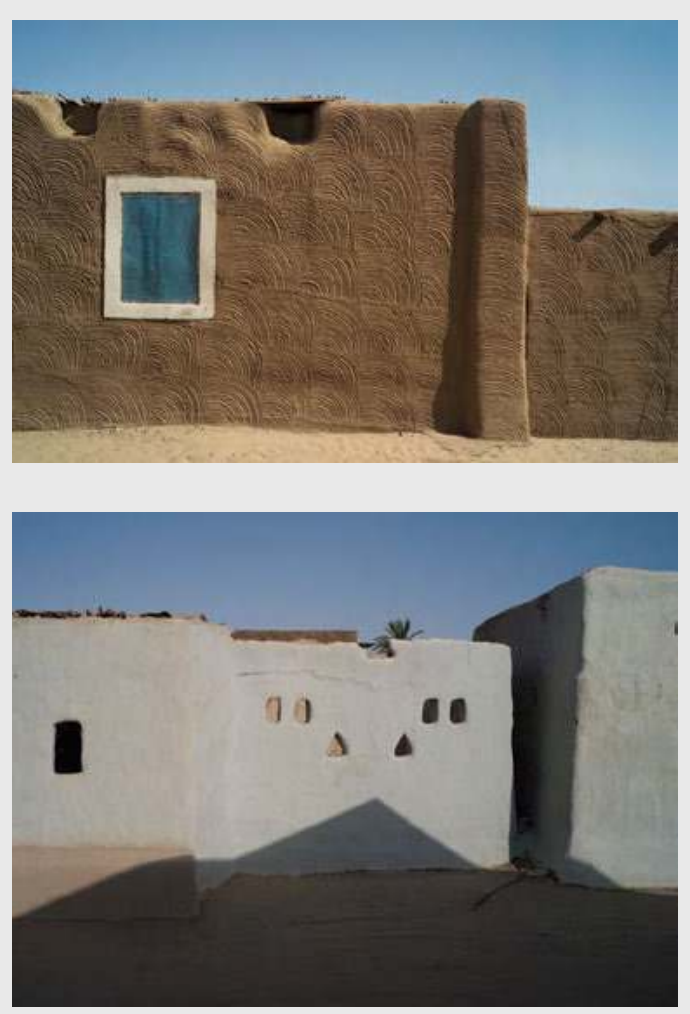

Île de Saï et environs de Soleb, nord du Soudan, 2015.
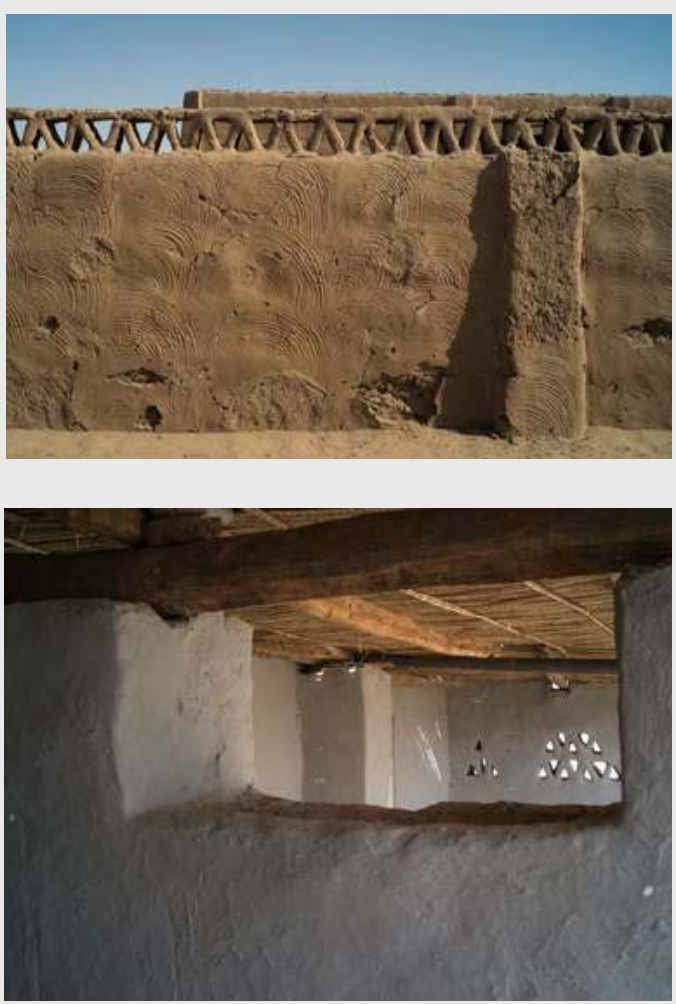

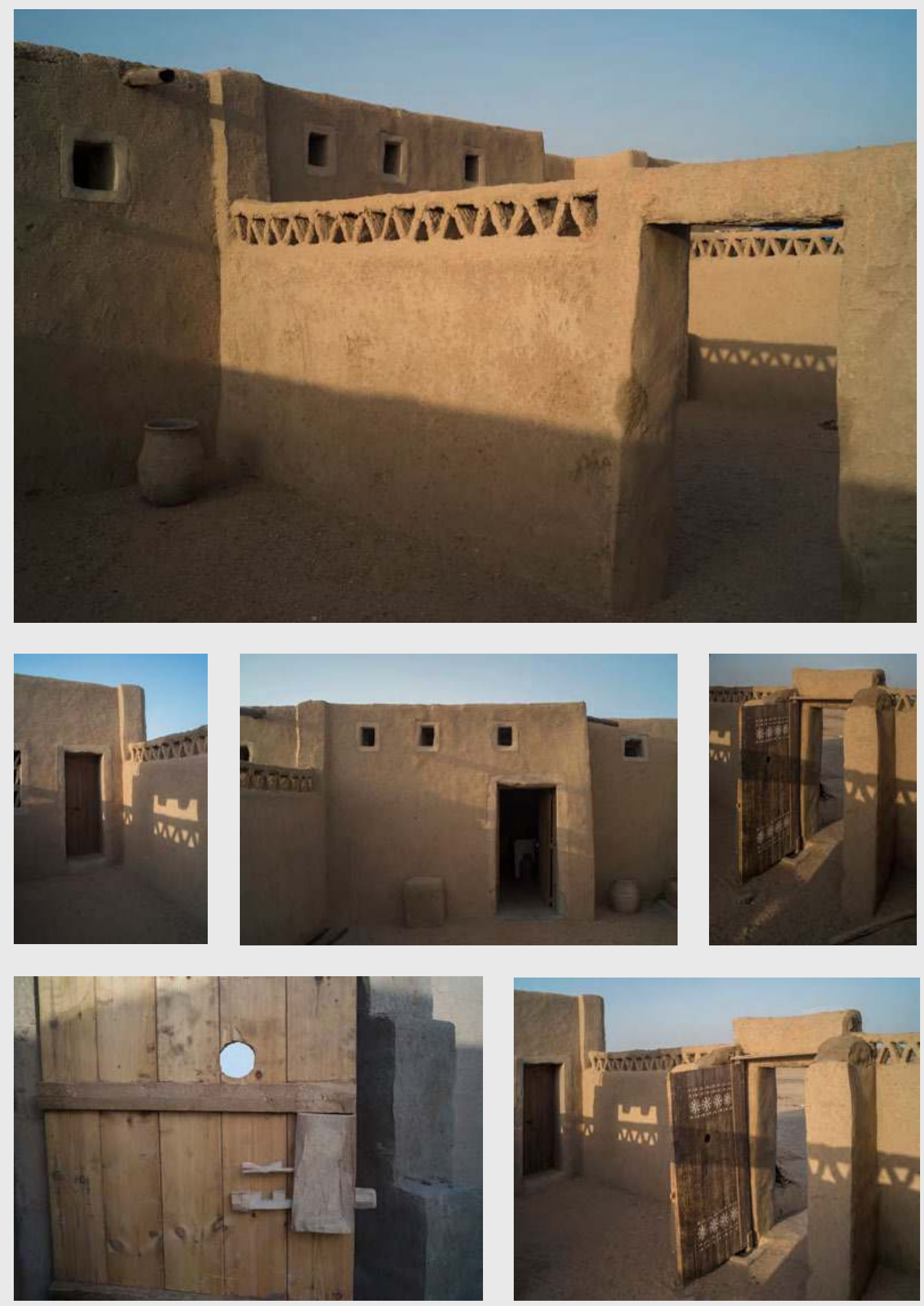

«Maison de fouilles» française de Sedeinga, construite en 1979 par Audran Labrousse et restaurée par Claude Rilly, 2015. 


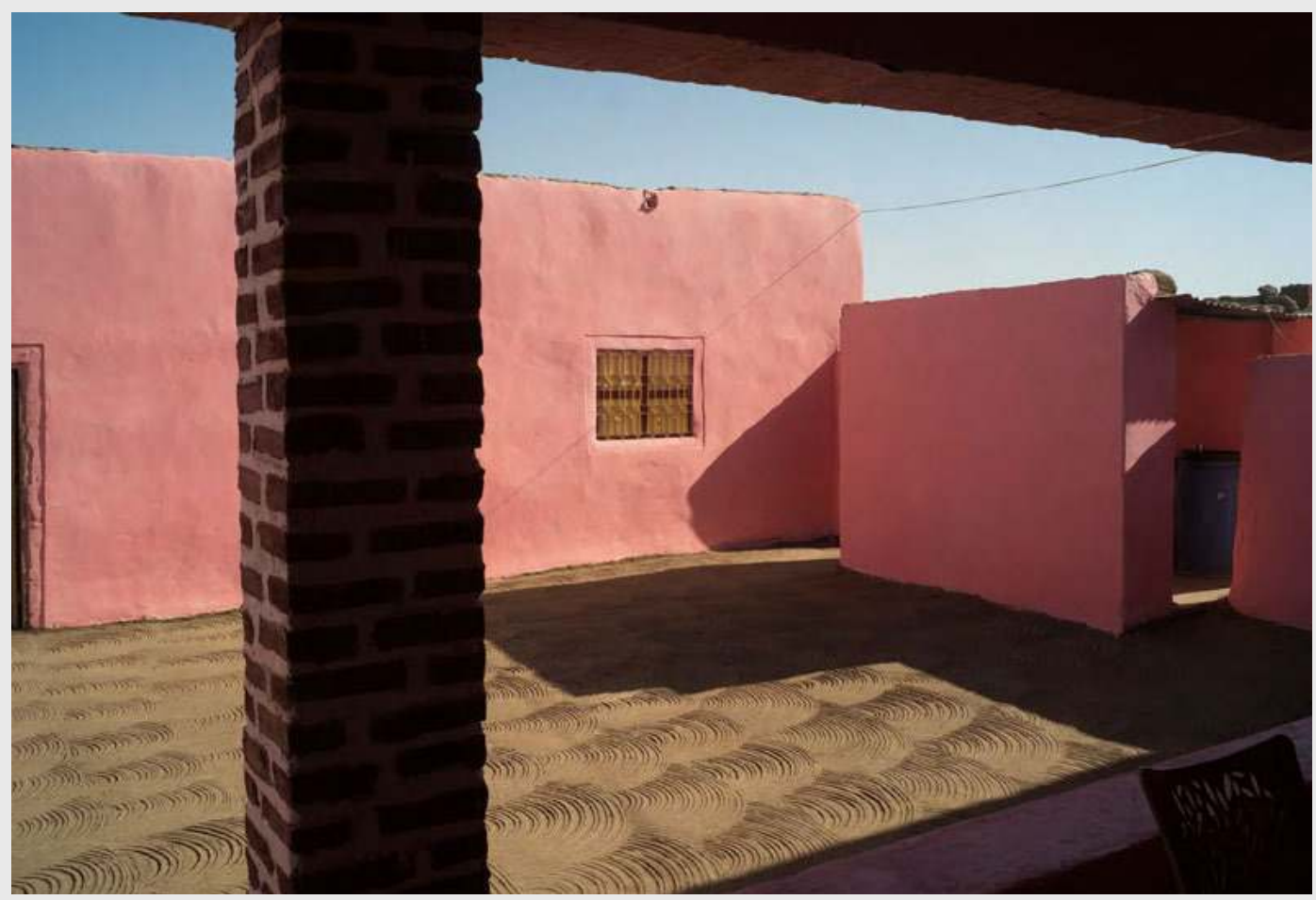

le Soudan

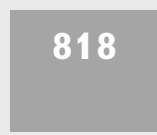

aujourd'hui
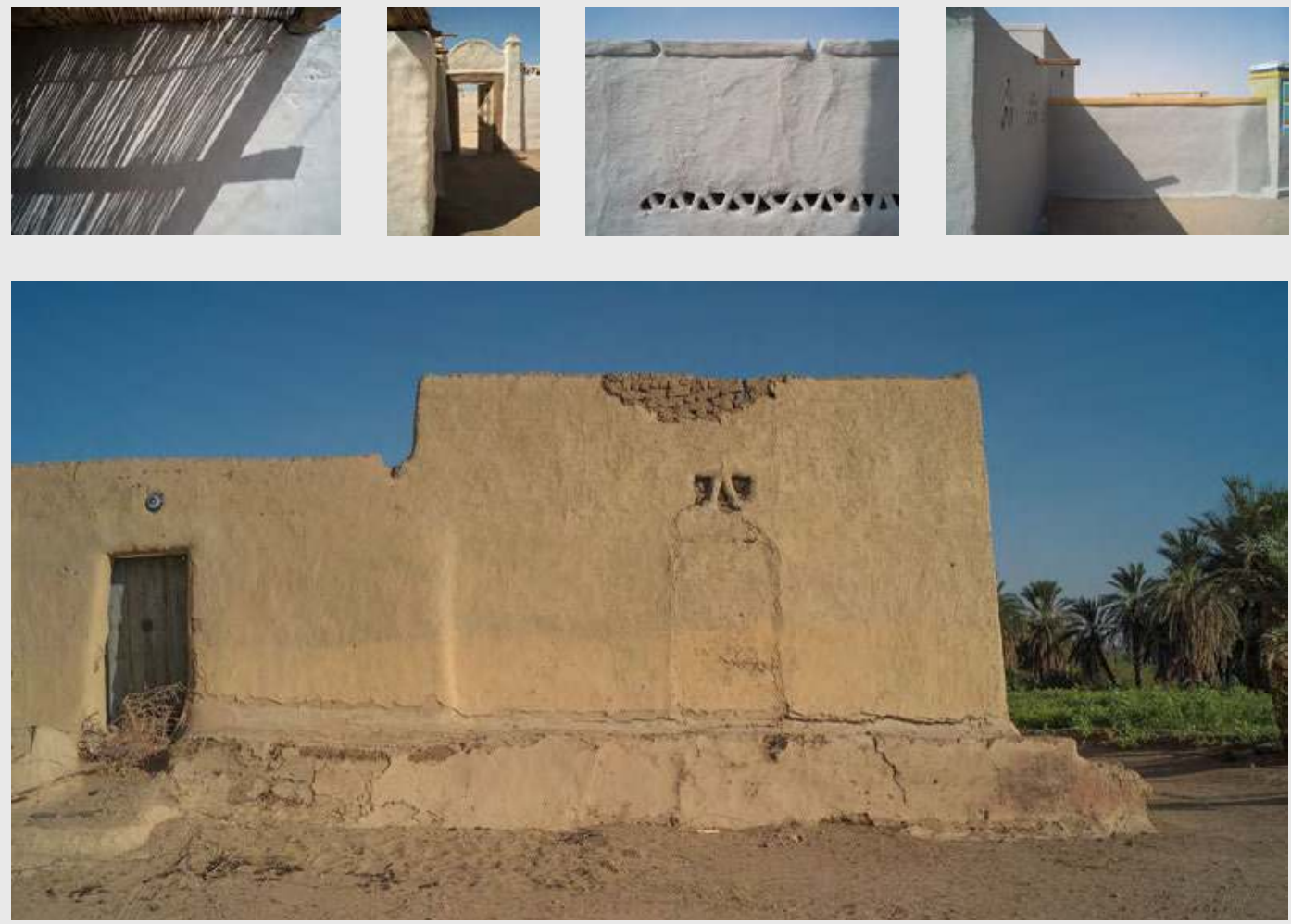

Île de Saï et environs de Soleb, nord du Soudan, 2015. 

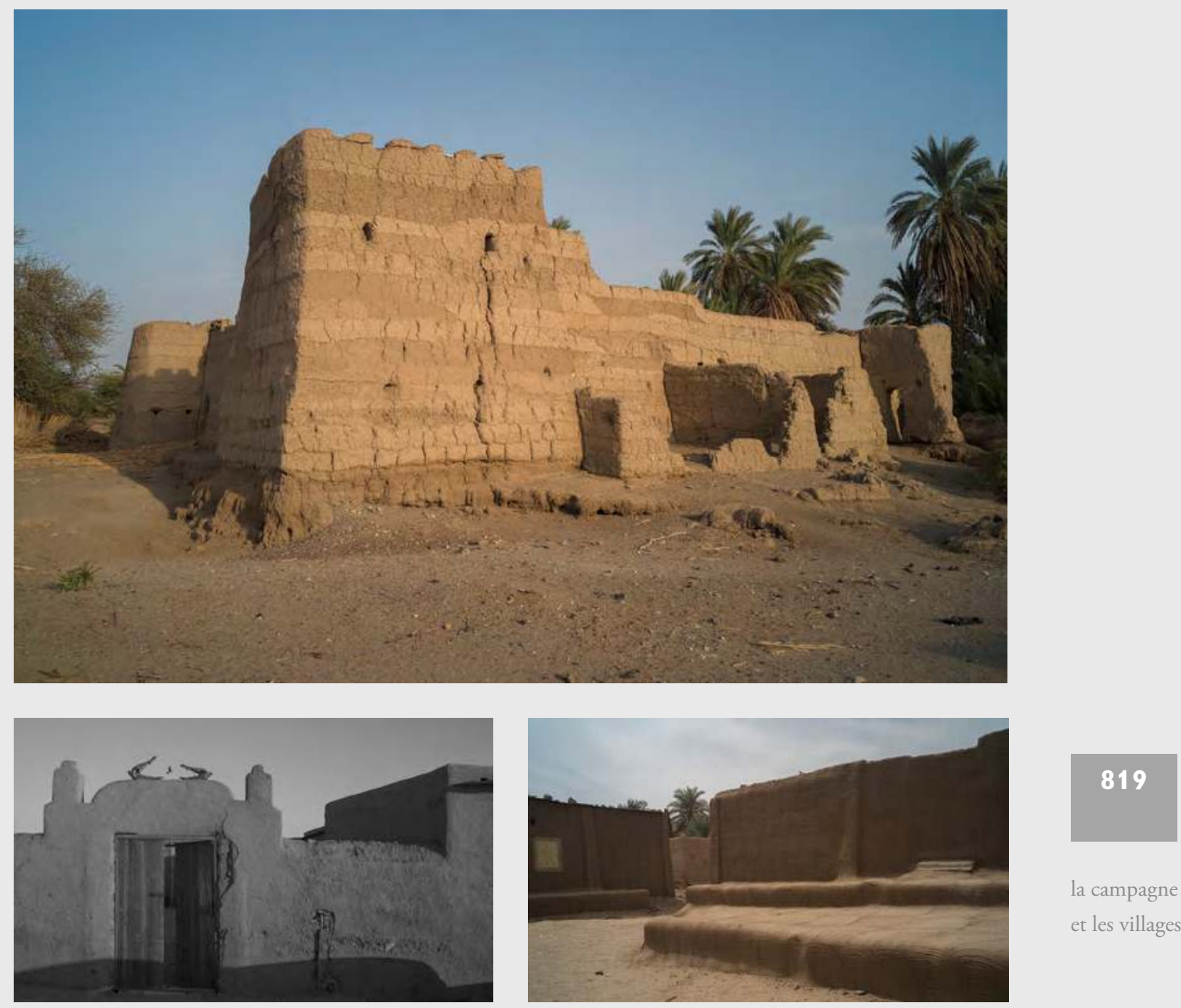

la campagne et les villages

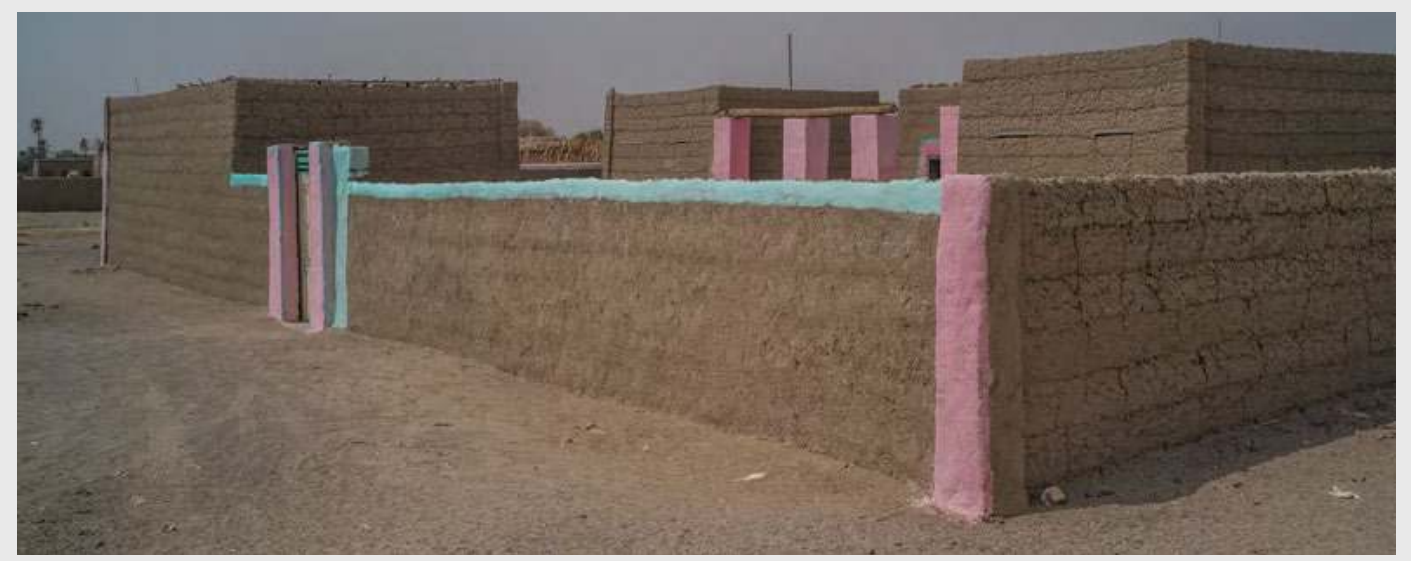

«Maison-tour » ancienne, abandonnée, et constructions récentes, île de Saï, 2015. 


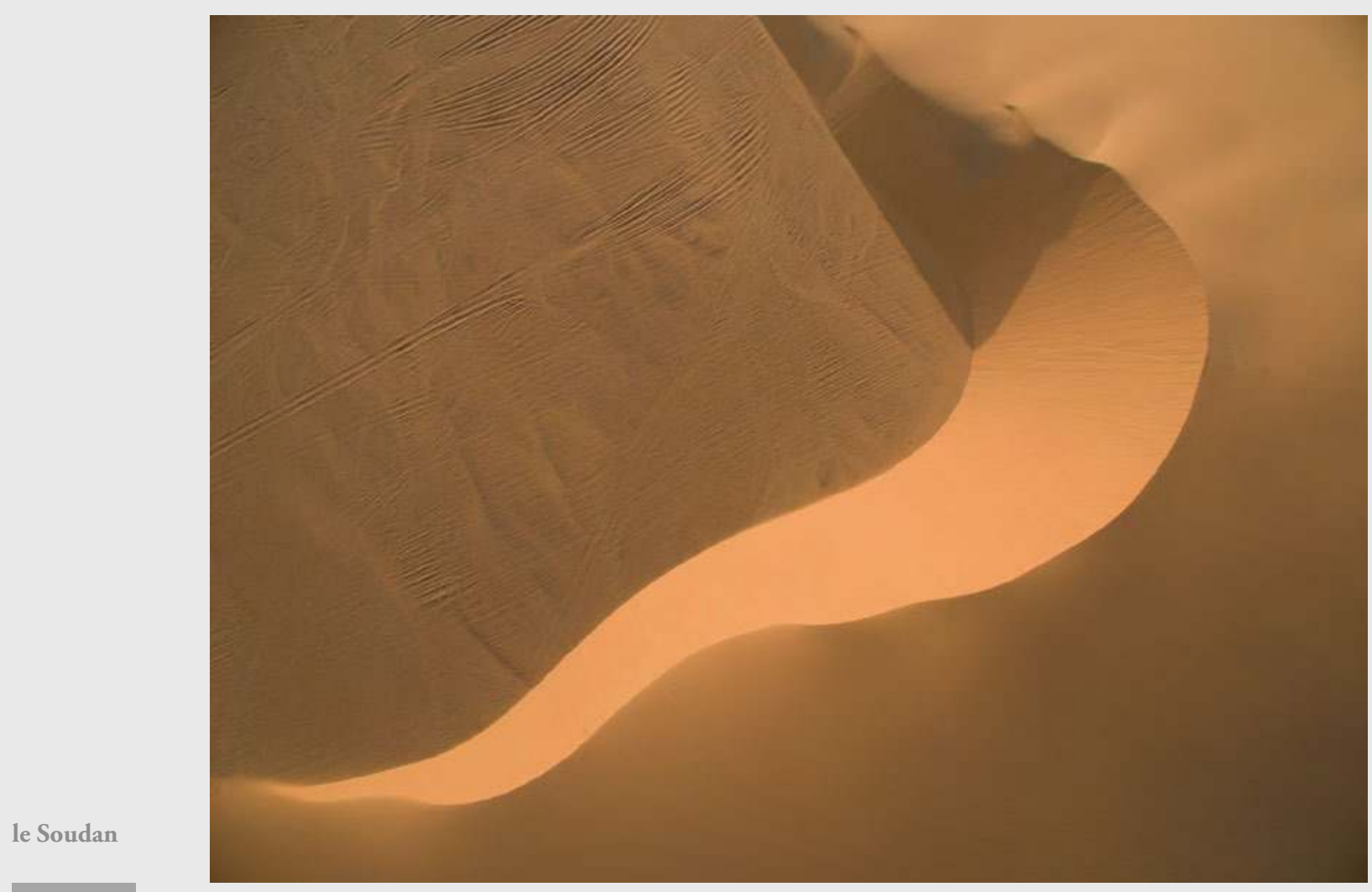

\section{0}

aujourd'hui

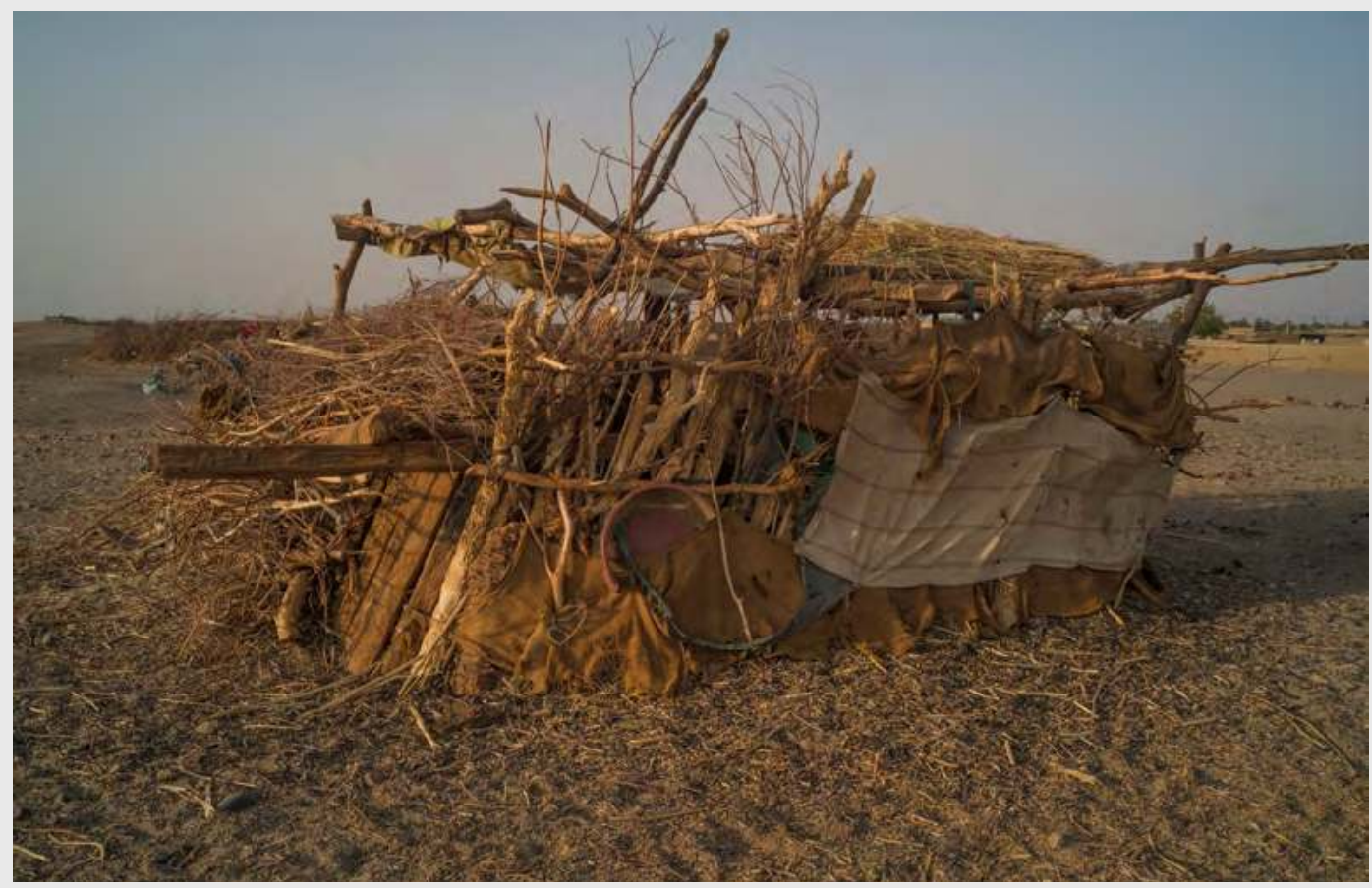

Barkhane sur la rive ouest du Nil en face de Saï ; enclos pour les chèvres et les moutons, 2015. 

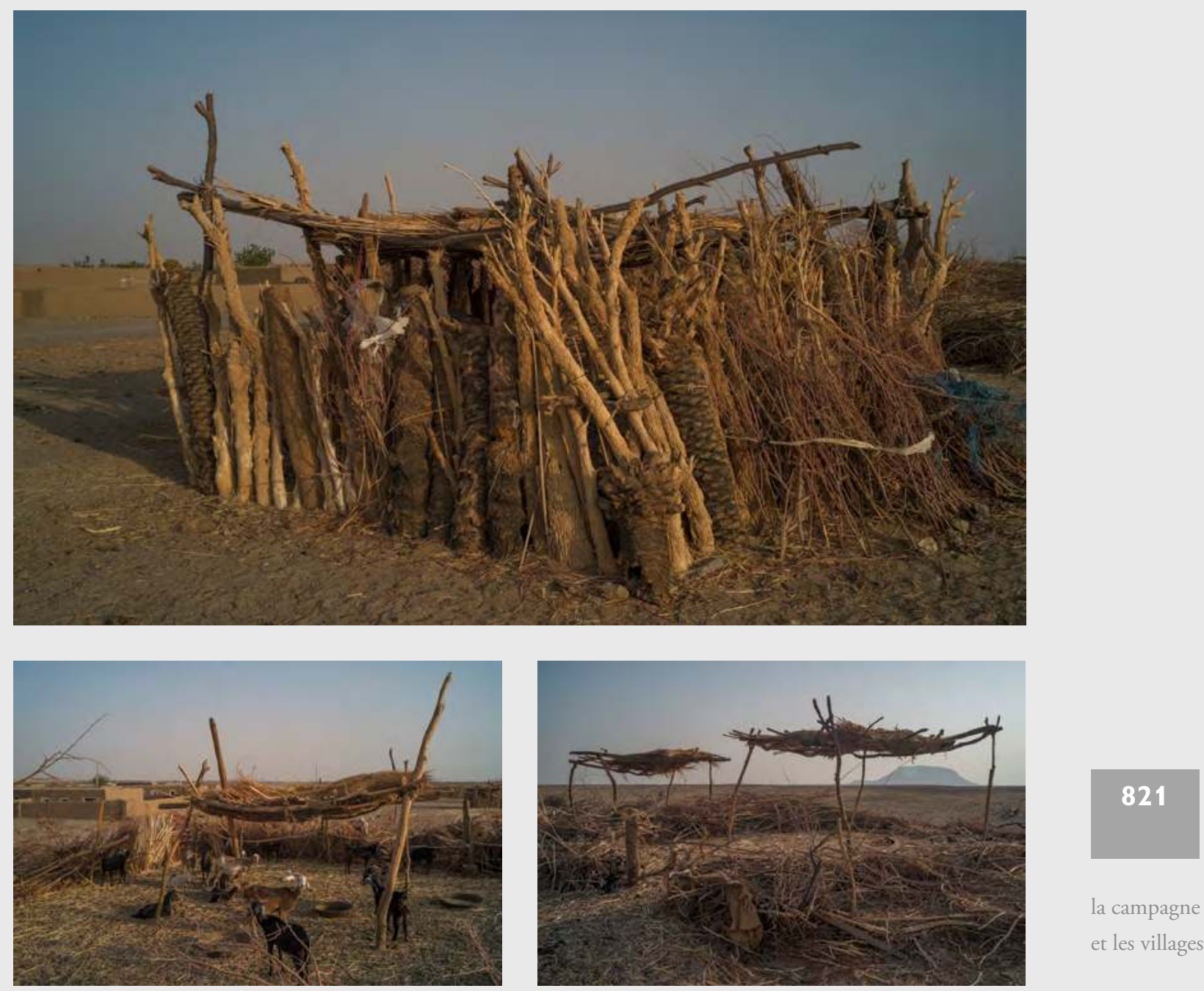

la campagne et les villages

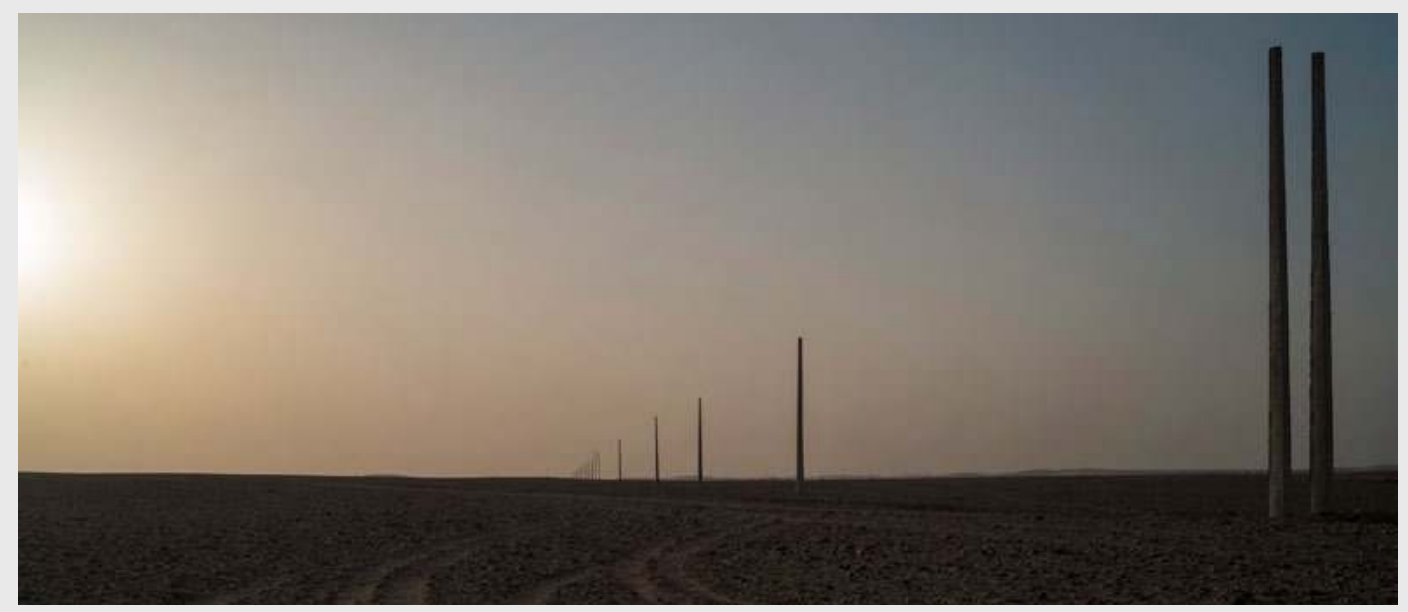

Enclos pour les chèvres et les moutons et arrivée de l'électricité, Saï, 2015. 